\title{
La ocupación CAMPANiforme del yacimiento de El Arsenal (Elche, Alicante)
}

The Bell-Beaker occupation of the Arsenal site (Elche, Alicante)

\section{ISRAEL SERNA MARTÍNEZ1 , GABRIEL GARCÍA ATIÉNZAR²}

(1) Investigador independiente. israelsr29@gmail.com (https: orcid.org/0000-0003-3543-8443)

(2) Instituto Universitario de Investigación en Arqueología y Patrimonio Histórico (INAPH). Universitat d’Alacant. g.garcia@ua.es (https://orcid.org/0000-0001-9390-8111)

\section{RESUMEN:}

En este trabajo se presentan los resultados relacionados con los niveles prehistóricos documentados durante la excavación de urgencia desarrollada en la finca de El Arsenal (Elche, Alicante). Durante esta intervención se documentó una estructura de carácter doméstico a la cual se asociaban un conjunto de estructuras subsidiarias, así como diferentes artefactos que permiten definir las características de una unidad doméstica de cronología campaniforme, así como las relaciones mantenidas con su entorno más inmediato. Este conjunto de evidencias permite caracterizar, por primera vez, a las comunidades humanas asentadas en el Bajo Vinalopó a mediados del III milenio cal BC a partir de sólidas bases cronoestratigráficas.

Palabras clave: Campaniforme, unidad doméstica, cerámica decorada, Calcolítico, Bajo Vinalopó.

\section{Abstract:}

This paper presents the results of the prehistoric levels documented during the commercial excavation carried out at the El Arsenal estate (Elche, Alicante). During this intervention, a domestic structure was documented to which a set of subsidiary structures were associated. These structures, as well as the different artefacts recovered, allow us to define the characteristics of a domestic unit with a Bell Beaker chronology, as well as the relationships maintained with its most immediate surroundings. This set of evidence makes it possible to characterise, for the first time, the human communities settled in the Bajo Vinalopo in the middle of the 3rd millennium cal BC on the basis of solid chronostratigraphic bases.

Key words: Bell Beaker, domestic unit, decorated pottery, Chalcolithic, Bajo Vinalopó. 
El desarrollo de la arqueología de gestión, especialmente en el ámbito urbano, ha implicado en las últimas décadas la generación de un importante conjunto de datos y secuencias cronoestratigráficas que han venido a completar, e incluso matizar, buena parte del conocimiento que tenemos sobre las sociedades pretéritas. Este hecho se hace aún más palpable en ciudades con una dilatada historia, como Elche, en tanto se ubican sobre nichos ecológicos favorables para el ser humano, especialmente a partir de la implantación de la economía basada en la agricultura y la ganadería y el desarrollo de los procesos de fijación residencial. En este sentido, la ocupación humana del tramo final del Vinalopó parece que se consolidó entre finales del VI e inicios del V milenio cal BC según evidencian los hallazgos recuperados en La Alcudia (Ramos Folqués 1954) o, más recientemente, en el asentamiento de Limoneros (Barciela et al. 2014; García Atiénzar et al.2020). A estas primeras evidencias neolíticas, caracterizadas arqueográficamente por cerámicas impresas e incisas, le siguieron ocupaciones asociadas al IV y III milenio cal BC definidas ahora por estructuras negativas tipo silo e, incluso, fondos de cabaña que se documentan en el entorno o bajo el propio solar de la ciudad de Elche (Ramos Folqués 1954; Ramos Molina 1989; Soler et al. 2014; Jover et al. 2014).

En este trabajo presentamos los resultados de la intervención de urgencia realizada en 2010 en el yacimiento de El Arsenal ${ }^{1}$. La información recuperada entonces y presentada ahora, aunque de manera parcial $^{2}$, supone un avance significativo para la construcción de la Prehistoria reciente del Bajo Vinalopó en tanto viene a completar la secuencia referida al Calcolítico final -Campaniforme-, momento ya conocido por hallazgos y excavaciones realizadas hace décadas, aunque ahora complementadas con datos cronoestratigráficos sólidos.

\section{EL YACIMIENTO DE EL ARSENAL (ELCHE)}

El yacimiento de El Arsenal se localiza en la finca homónima, concretamente en una de las terrazas de la margen izquierda del río Vinalopó, a unos $250 \mathrm{~m}$ del cauce-UTM X: 701438 Y: 4236354-, dentro del denominado Sector E-16 Portes Encarnades, a $2 \mathrm{~km}$ al S del centro de la ciudad de Elche y a 1,5 km del yacimiento de La Alcudia (fig. 1).

La primera referencia al sitio la encontramos en documentos de principios del siglo XX (Ibarra Ruiz 1926: 39), que lo sitúan al S del municipio de Elche (Alicante) en la partida también conocida como de Granados d'Espuig. En esta misma década se documentaron restos arqueológicos asociados a diferentes momentos de ocupación, entre los que cabe destacar un alfar ibérico en torno al cual se recuperaron cerámicas de esta misma cronología, un clavo de hierro y fusayolas (op . cit.). Años más tarde, Ramos Folqués (1953) vuelve a relacionar estos hallazgos, aunque sin apuntar más datos que los referidos anteriormente.

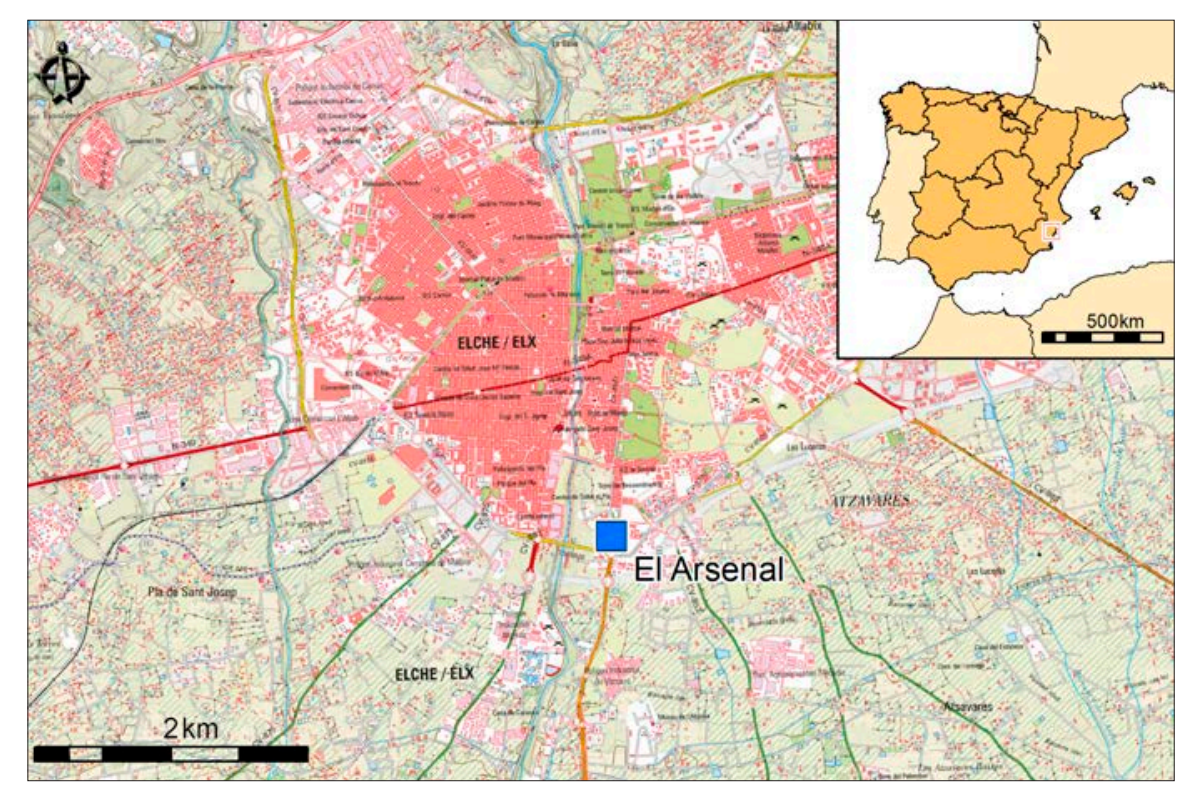

Fig. 1: Mapa de ubicación del yacimiento de El Arsenal en el marco del Bajo Vinalopó. 
Fig. 2: Planimetría del área de excavación con la representación de las diferentes fases cronoestratigráficas identificadas.

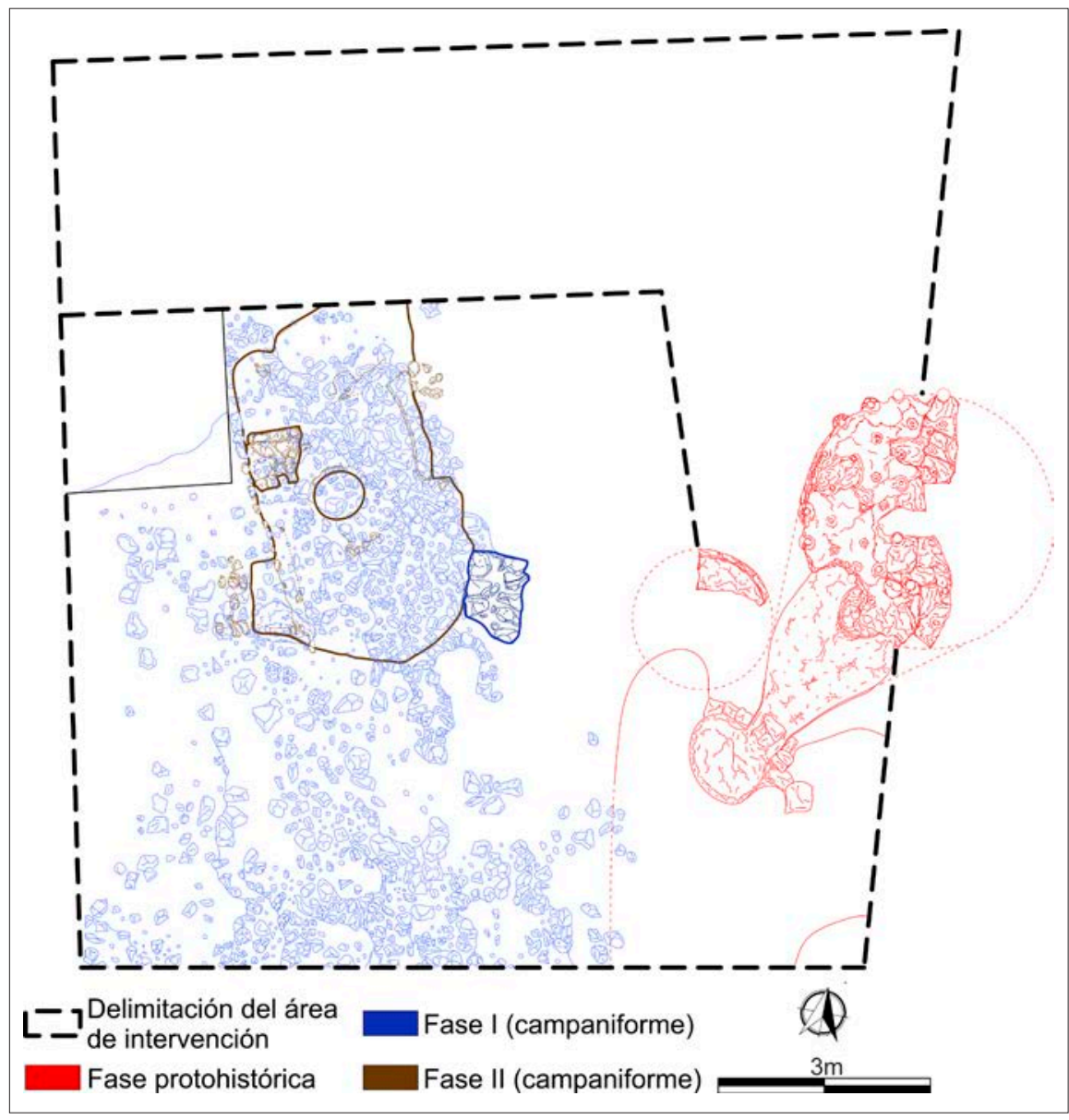

En 1991 se intervino por primera vez de manera sistemática, documentándose siete enterramientos de época romana -doce individuos-, parte de una calzada y otras construcciones parcialmente excavadas (López Seguí 1995). Debemos destacar que en los sondeos realizados a raíz de esta intervención se documentaron otras estructuras -dos hornos, tres testares, etc.- datadas en el s. IV a.C. (López Seguí 2000). Todos los restos se asociaron al yacimiento de La Alcudia por su cercanía y por la identificación de la mencionada vía de comunicación.

Finalmente, en 2010 se retomaron las actuaciones arqueológicas en la zona, esta vez de manos de la empresa Alebus Patrimonio Histórico S.L.U., actuándose en la zona sondeada en 1991 con el objetivo de documentar de manera completa el alfar ibérico. La excavación, promovida por la sociedad AIU Portes Encarnades para la posterior edificación de la parcela, se llevó a cabo entre finales de mayo y comienzos de julio, documentándose un total de 48 unidades estratigráficas que abarcaban desde períodos cronológicos contemporáneos -UUEE 10001003 y 1007-1009-, de época ibérica -UUEE 10101021, 1004-1006 y 1047- y de cronología prehistórica -UUEE 1022-1046- (López Seguí y Espí 2010) (fig. 2). En este trabajo nos centraremos en las unidades de cronología prehistórica, pudiéndose destacar una estructura de hábitat, de la cual ya se han presentado algunos avances (Serna 2019), que, por los materiales asociados y la datación radiocarbónica obtenida, podemos situar dentro del Campaniforme.

\section{SECUENCIA ESTRATIGRÁFICA, ESTRUCTURAS DOMÉSTICAS Y ÁREAS DE ACTIVIDAD}

Durante el proceso de excavación se documentó una interesante sucesión de estratos, todos ellos vinculados con materiales prehistóricos, que pueden asociarse tanto a niveles de ocupación como de abandono, así como a 
diferentes estructuras construidas o negativas (López Seguí et al. 2010). A grandes rasgos, pueden establecerse dos momentos de ocupación, posiblemente sucesivos y asociados al Campaniforme si atendemos a su registro material, relacionados con dos construcciones bien diferenciadas estratigráficamente, a las cuales se asocian sendos niveles de derrumbe. Además de estos dos episodios, cabe destacar la existencia de algunas unidades estratigráficas relacionadas con un sondeo realizado al NO del sector excavado. Durante dicha intervención, efectuada a la par que la propia excavación, se documentan dos rellenos sedimentarios (UUEE 1025 y 1026) con materiales arqueológicos prehistóricos de difícil adscripción debido a sus características y estado de conservación.

\section{FASE 1}

Por debajo de los niveles protohistóricos, y cubierta por un potente estrato formado por capas superpuestas de arenas, gravas y arcillas que se relacionan con sucesivos aportes fluviales y aluviales, se documentó la UE 1027, un nivel compuesto por piedras y cantos, con hasta tres

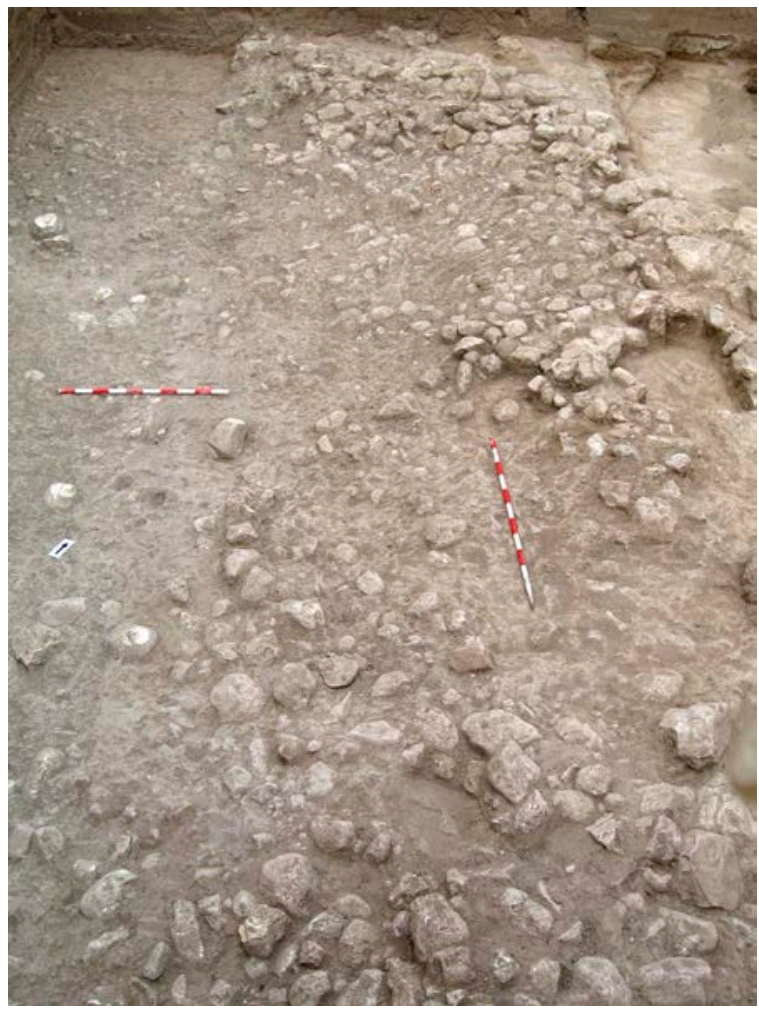

Fig. 3: Vista general del nivel de derrumbe UE 1027 antes de su excavación. capas en la zona de mayor acumulación, y una matriz arenosa entre la cual se documentaron fragmentos de revoco, de fauna y de elementos de molienda, posiblemente reutilizados como mampuestos, que permite interpretar este estrato como un nivel de derrumbe (fig. 3). Durante la excavación de este nivel se individualizó la UE 1029, una alineación de bloques y piedras de la cual solo se conservaba una hilada, de orientación N-S, que preservaba una longitud mínima de 1,20 m y una anchura de $0,54 \mathrm{~m}$ (fig. 4).

Si bien lo conservado es muy limitado, sus características encajan con lo que podría haber sido el muro de delimitación de algún tipo de estructura, aunque resulta imposible establecer su funcionalidad. Del derrumbe se obtuvo una datación radiocarbónica a partir de un fragmento de fauna no identificable que fecha la destrucción de esta estructura en 3870 \pm 30 BP (2465-2211 cal BC) (fig. 5), así como el abandono definitivo de este espacio tras la amortización de los niveles de ocupación asociados a la Fase 2.

\section{FASE 2. ESTRUCTURA DE HÁBITAT 1}

Por debajo de las unidades vinculadas a la Fase 1, y prácticamente en la misma vertical, aunque sin que se pueda establecer si entre ambas fases hubo o no solución de continuidad, se documentaron las UUEE 1031 y 1032, unidades definidas por sedimento areno-arcilloso, compacto y mezclado con restos de revoco rubefactado, cenizas y carbones, además de piedras calizas de tamaño mediano, que debemos interpretar como los niveles de incendio y derrumbe de la estructura infrayacente.

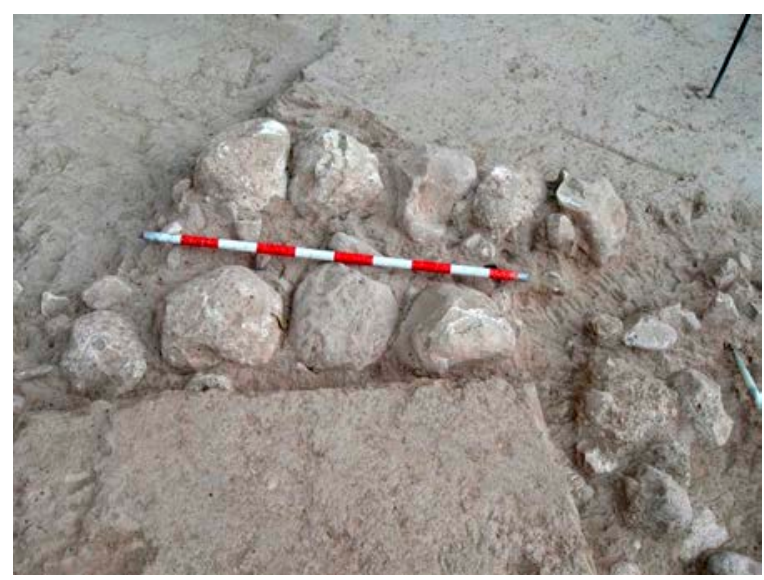

Fig. 4: Detalle de la estructura muraria UE 1029. 


\begin{tabular}{|c|c|c|c|c|c|c|}
\hline Muestra & Contexto & Ref. Lab. & BP & Cal BC 2s & $\boldsymbol{\delta 1 5 N}(\%)$ & $\boldsymbol{\delta} 13 \mathrm{C}(\%)$ \\
\hline \multirow{3}{*}{ Fauna } & UE 1027 & Beta 522022 & $3870 \pm 30$ & $\begin{array}{c}(87,8 \%) 2462-2282 \\
(5,1 \%) 2251-2231\end{array}$ & +8.61 & -19.8 \\
& & & & $(2,6 \%) 2222-2209$ & & \\
\hline
\end{tabular}

Fig. 5: Datación radiocarbónica del contexto de abandono de la Fase 1 (Calibración OxCal 4.4 IntCal20; (c) Bronk Ramsey 2020; Heaton et al. 2020).

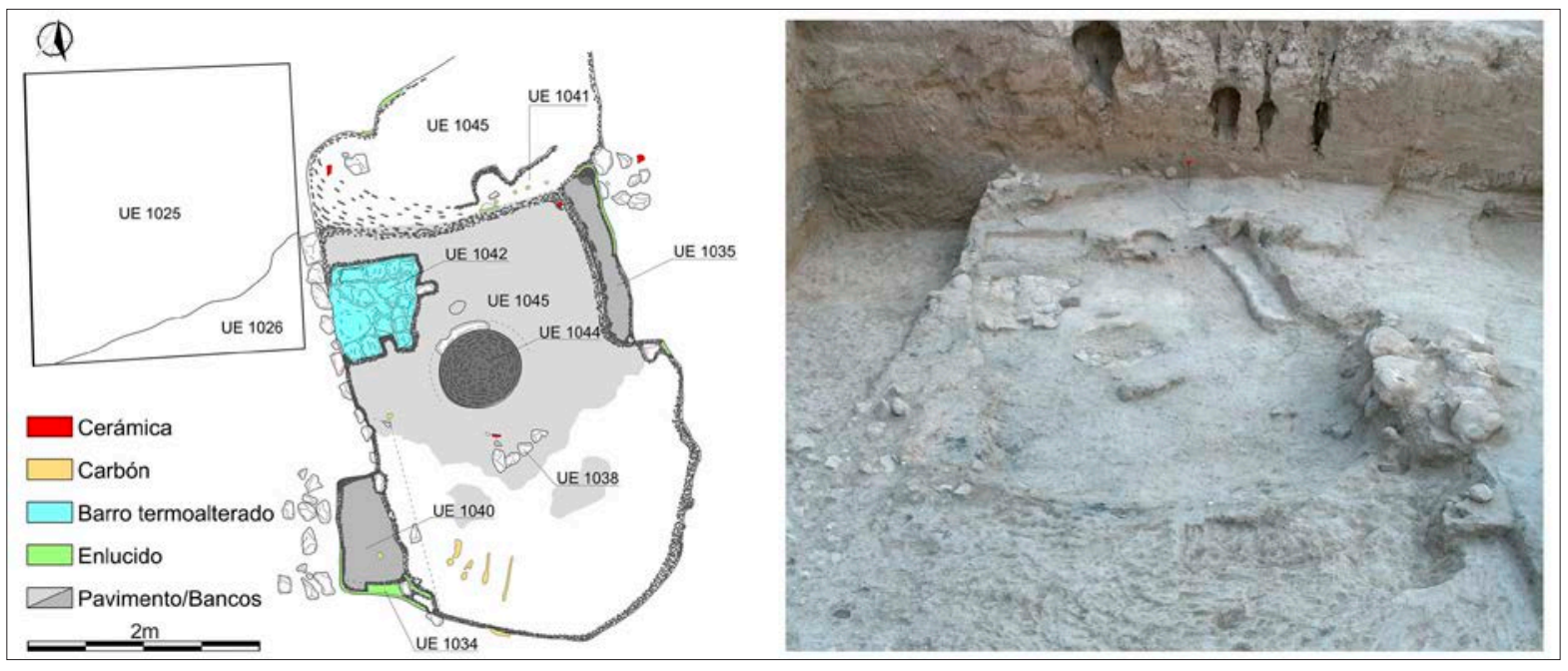

Fig. 6: Planta del fondo de cabaña (Estructura de hábitat 1, UE 1033) e imagen de ésta y de la UE 1027 -derecha- a la finalización de la excavación.

La estructura de hábitat 1 se define por estar semiexcavada y rehundida en la base geológica (UE 1025) (fig. 6), pudiéndose interpretar como un fondo de cabaña-UE 1033-, de orientación SO-NE según su eje longitudinal y de planta rectangular con los ángulos ligeramente redondeados, una anchura de 2,58 $\mathrm{m}$ y una longitud de 5,12 m, que cubría una superficie de 11,30 $\mathrm{m}^{2}$. Debe señalarse, sin embargo, que estas medidas deben ser entendidas como incompletas en tanto parte de la estructura se encontraba parcialmente arrasada en su lado meridional y occidental. En el lado O se documentaron una serie de piedras alineadas que podrían haber constituido la base sobre la que asentó el muro perimetral, aunque, y al igual que sucede con otras estructuras de este tipo localizadas en el SE y levante peninsular, el material constructivo básico fue el barro, habiéndose conservado este material en partes de los alzados de las paredes -ángulos N, E y $\mathrm{SO}-$, y estructuras interiores -bancos, hogar, etc.-, pero también en forma de fragmentos de pequeño y mediano tamaño en el derrumbe.

Durante el proceso de excavación del interior de la estructura de habitación se documentaron dos suelos o niveles de pavimentación. La UE 1045, correspondiente al pavimento original, mejor conservado en la zona central, estaba formada por una capa de barro aplicada sobre el suelo de tierra y presentaba un color rojizo y una superficie superior alisada, aunque con un ligero buzamiento descendente hacia la zona S. El segundo pavimento (UE 1036) estaba formado por una capa de tierra apisonada mezclada con cenizas y carbones, pudiéndose interpretar como una posible reparación del pavimento original.

En cuanto a las estructuras interiores, se documentaron diferentes elementos que se pueden relacionar, en gran medida, con diferentes actividades de hábitat y consumo (Serna 2019: 15). Una de las estructuras centrales de la cabaña, tanto por su localización como por su función, es el hogar circular (UE 1044) que presentaba un diámetro de $0,70 \mathrm{~m}$ y paredes de barro endurecido. A esta estructura se asocia un nivel de abandono (UE 1037) y su correspondiente relleno (UE 1039), donde aparecieron restos de vasijas. La UE 1038, definida como una alineación de piedras dispuestas radialmente y a $50 \mathrm{~cm}$ al $\mathrm{S}$ de la estructura de combustión, se puede interpretar como un posible anillo 
delimitador de dicha estructura. Junto a este hogar se documentó una estructura negativa de tipo cubeta (UE 1046) de planta elíptica con $25 \mathrm{~cm}$ de largo, $15 \mathrm{~cm}$ de ancho y $10 \mathrm{~cm}$ de profundidad, rellenada de tierra arenosa rojiza con carbones. La UE 1042, estructura también asociada al espacio interior y al pavimento original, aunque de más difícil interpretación, apareció conservada parcialmente. Se definía por una placa de forma rectangular $(84 \mathrm{~cm}$ de longitud $\mathrm{x}$ $78 \mathrm{~cm}$ de anchura) formada por sucesivas capas de barro termoalterado. Si bien su estado de conservación impide valorar apropiadamente su funcionalidad, su proximidad al hogar posibilita su relación con sus diferentes actividades domésticas y culinarias.

Asociadas al perímetro interior de la cabaña se documentaron hasta tres bancos, todos ellos excavados en la tierra, formando así parte de la propia estructura. Estaban enlucidos con el mismo revoco que las paredes que, a su vez, estaba sujeto por un entramado de cañas, como muestran los carbones alineados documentados en el banco UE 1041. El banco UE 1040 se situaba en el ángulo SO de la cabaña, conservando unas dimensiones de 1,51 m de longitud y $0,23 \mathrm{~m}$ de anchura y un alzado de entre 2 y $3 \mathrm{~cm}$. El resto de los bancos se encontraban en el ángulo NE. El banco UE 1035, de planta rectangular (1,50 m de longitud y $0,24 \mathrm{~m}$ de anchura), destacaba por presentar un posible calzo de poste que debemos relacionar con la sujeción de la techumbre de la cabaña. Por último, el tercer banco (UE 1041), que debemos interpretar como una extensión del anterior, apareció parcialmente arrasado, conservando una longitud de 0,72 $\mathrm{m}$ y una anchura de $0,30 \mathrm{~m}$.
Por otro lado, y también alrededor de la cabaña, se documentaron restos de derrumbes de otras dos posibles cabañas, aunque la documentación de ambas estructuras no resultó posible ya que en la primera los restos se desarrollaban bajo la cámara de combustión del horno ibérico, que se preservó in situ, mientras que en la segunda se encontraban fuera de los límites de la intervención. Todo este conjunto de información nos habla de una intensa ocupación de la zona durante la segunda mitad del III milenio cal BC, refrendada recientemente por la documentación de nuevas estructuras en sectores aledaños (López Seguí c.p.).

\section{EL REGISTRO MATERIAL}

La excavación de El Arsenal permitió recuperar un significativo conjunto de artefactos que permiten una mejor contextualización de esta ocupación (fig. 7), pudiéndose destacar una gran cantidad de fragmentos cerámicos (785) documentados a lo largo de las diferentes unidades estratigráficas. Por detrás, destacan otros artefactos como útiles líticos, tallados y pulidos, o restos de malacofauna, fundamentalmente aprovechados como elementos de adorno. Junto a estos artefactos, encontramos una amplia cantidad de fragmentos de barro que debemos relacionar con el material constructivo de la cabaña 1, habiéndose constatado improntas de ramaje. También se recuperaron ecofactos de diferente naturaleza, aunque su estudio resultó imposible.

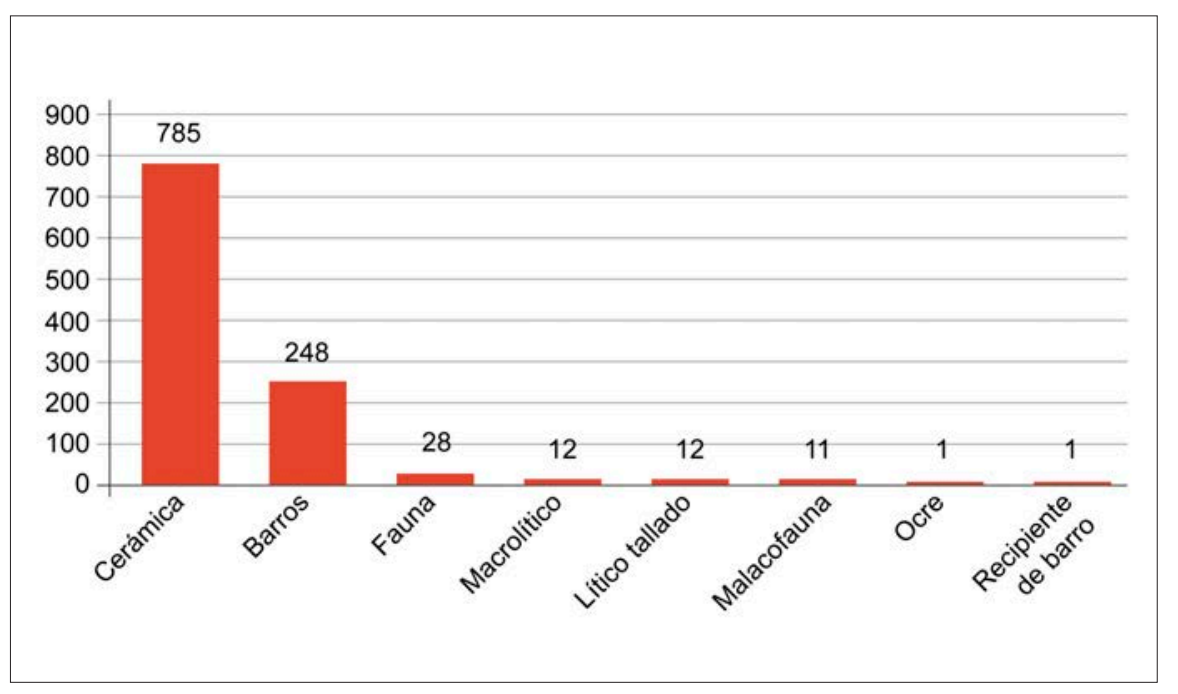

Fig. 7: Representación gráfica del total de artefactos y ecofactos inventariados. 


\section{LA VAJILLA CERÁMICA}

El amplio número de fragmentos cerámicos se documentan desde los últimos niveles de amortización hasta los vinculados a la cabaña, incluyendo los rellenos de las estructuras internas. Para su estudio, nos centraremos en los fragmentos que aportan datos de carácter morfotipológico (116: 13,3\%), discriminando los restantes (669: $86,7 \%$ ), empleando para ello las propuestas de otros investigadores aplicadas a contextos similares (Soler Díaz 2002; Jover y Torregrosa 2010; Jover et al. 2012; García Atiénzar 2010).

\section{DESCRIPCIÓN MORFOTIPOLÓGICA}

Se documentaron un total de 93 fragmentos con información relativa al labio, la mayor parte de tipo redondeado o convexo (52 fragmentos) que suponen algo más de la mitad del conjunto $(55,9 \%)$. Por detrás se situarían los labios planos (13), apuntados (siete), así como diferentes tipos de engrosados: engrosamiento doble plano (dos), engrosamiento exterior plano (cuatro) y engrosamiento exterior redondeado o convexo (diez). Por último, se documentan dos tipos de biselados: biselado interior plano (dos) y biselado interior redondeado (tres).

En el conjunto de bordes (93) destacan los rectos salientes (RTS: 24; 25,8\%) y los cóncavos entrantes (CVE: $22 ; 23,7 \%)$. Por detrás se situarían los bordes rectos (RT) y los cóncavos salientes (CVS), con 12 y 11 fragmentos, respectivamente. Los bordes convexo saliente (CXS) y los bordes rectos entrante (RTE) suponen el 8,6\% (ocho) y el 3,2\% (tres), respectivamente. Destaca el alto número de cerámicas no orientables a causa de la erosión, siendo el tercer grupo más representado con un $14 \%$.

En cuanto a los apliques (11 fragmentos), cabe señalar la presencia de mamelones (ocho), siempre próximos al labio, de tipo circular, dos cordones horizontales y un único fragmento de asa asociada a un gran recipiente que no ha podido ser restituido.

Por último, se documentaron tres tipos de bases: convexa (una), plana talonada (tres fragmentos asociados a un mismo vaso) y aplanada (nueve), además de un ejemplar de morfología indeterminable por su erosión y fracturación.

\section{APROXIMACIÓN TECNOLÓGICA}

La cocción e inclusiones registradas son muy variadas, sin poder determinarse un patrón claro, incluso si solo se toman en consideración los fragmentos decorados. En líneas generales, se ha documentado un alto número de fragmentos con atmósferas reductoras (76: 62,8\%) con pastas de colores grisáceos y negros. La cocción oxidante (33 fragmentos: 27,3\%) se determina en fragmentos con pastas de colores amarillentos, ocres, marrones o naranjas. Por su parte, se registraron también cocciones mixtas o alternantes, aunque con porcentajes por debajo del $4 \%$.

Sobre los desgrasantes, y siempre desde un punto de vista macrovisual, predominan las inclusiones calizas, aunque también se documentan granos de cuarcita y mica y, de manera testimonial, chamota. En algunos fragmentos se ha observado la presencia de, al menos, dos tipos diferentes de inclusiones en la pasta de la cerámica. Destaca, por último, una alta representación de fragmentos $(21,3 \%)$ en las cuales el desgrasante resulta inapreciable.

En cuanto al tratamiento de las paredes, tanto en la cara exterior como en la interior, predomina el alisado. Solo un par de fragmentos presentan un tratamiento grosero y algunos ejemplares presentan paredes erosionadas y con concreciones. Cabe destacar la falta de otro tipo de tratamientos como pueden ser los bruñidos o espatulados, aspecto en el que puede haber incidido los importantes procesos de alteración postdeposicional sufridos por el depósito.

Por último, sobre los grosores de los fragmentos cerámicos, debemos destacar la existencia de cerámicas con paredes tanto finas como más gruesas. Encontramos fragmentos que responderían a pequeños recipientes cerámicos, entre los 5 y los $8 \mathrm{~mm}$ de grosor, aunque existen bastantes casos con grosores superiores a los $10 \mathrm{~mm}$, llegando en algún caso a los $19 \mathrm{~mm}$, en relación sobre todo con las bases. Aunque no se pueda realizar una correlación directa por falta de datos, sí podemos inferir un variado conjunto de vasos, tanto de pequeño como de gran tamaño, en relación con las distintas actividades domésticas que se realizarían en los diferentes contextos determinados.

\section{LOS FRAGMENTOS DECORADOS}

Se documentaron un total de 14 fragmentos decorados, lo cual supone menos del $1 \%$ del registro formal, dato similar al ofrecido por otros contextos domésticos asociados al Campaniforme peninsular (Garrido 20122013: 47). El soporte es variado, encontrando dos bordes y cuatro galbos, así como un vaso parcialmente restituible formado por ocho fragmentos informes (fig. 8, 102206), que podría contar con más fragmentos en otros niveles de abandono (fig. 8, 1023-03), lo cual denota una 


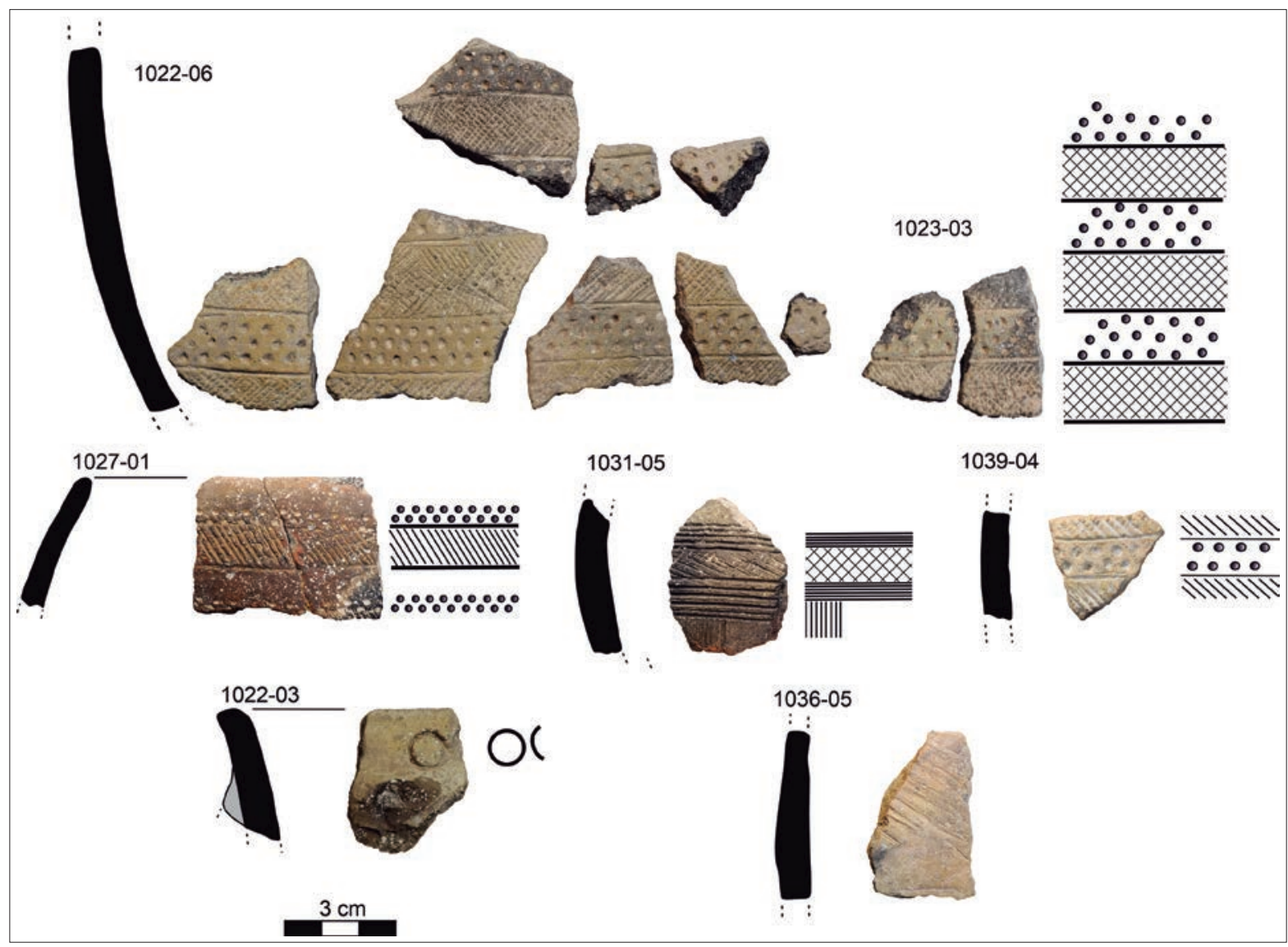

Fig. 8: Repertorio cerámico decorado.

cierta movilidad vertical a lo largo de la estratigrafía. Las decoraciones se enmarcan en los llamados estilos tardíos (Bernabeu 1984; Juan-Cabanilles 2005; Alba Luzón 2016) definidos, en este caso, por técnicas incisas e impresas -puntillado- a través de las cuales se definen esquemas decorativos a base de bandas horizontales alternas (líneas oblicuas, reticulados, series de puntos, etc.), por norma general delimitadas mediante líneas incisas, dispuestas en la parte superior y central del vaso, rematadas en el tercio inferior por bandas verticales o series de triángulos de similar composición que tienden a converger en la base (fig. 8). Este repertorio recuerda al documentado en el Promontori de l'Aigua Dolça i Salà (Ramos Fernández 1981; 1983; 1984a; 1984b), pero también en otros contextos del Vinalopó, especialmente en lo que refiere a los patrones decorativos, encajando bien en el denominado "estilo Elche" (Ramos Fernández 1986) y el "estilo regional valenciano" (Bernabeu 1984; Juan-Cabanilles 2005). Debe señalarse, por otra parte, la presencia de un fragmento decorado con un motivo aislado a modo de círculos incisos dispuestos cerca del labio (fig. 8, 1022-3), decoración que no encaja dentro de la norma campaniforme.

Debe destacarse que un ejemplar conservaba el relleno de las decoraciones mediante pasta de color blanco, aunque no pudieron realizarse análisis específicos. Tomando en consideración analíticas realizadas en otros yacimientos peninsulares, estos rellenos podrían haberse obtenido a partir de yeso, hueso, talco o carbonato cálcico (Odriozola et al. 2012; Odriozola 2019; Molina et al. 2017).

La limitada presencia de cerámica decorada (14 fragmentos) frente a los no decorados (771), revelaría que este tipo de recipientes no tendrían un peso significativo en el desarrollo de la mayor parte de las actividades cotidianas. Hace ya décadas, Bradley (2005) puso de manifiesto la imposibilidad de separar el ámbito simbólico del ámbito doméstico, especialmente en lo que refiere a la 
consideración ritual de la vajilla campaniforme. Su carácter minoritario en contextos domésticos, así como sus características tecnológicas -poco aptas para usos culinarios- y morfológicas, han permitido proponer la consideración ritual de esta vajilla en diferentes ámbitos peninsulares (Garrido 2012-2013: 53; Molina et al. 2017: 270). Esta consideración resulta especialmente significativa en diferentes territorios campaniformes peninsulares, como Ciempozuelos (Guerra y Delibes 2019: 230), relacionándose esta vajilla con ceremoniales articulados en torno al consumo de alimentos y bebidas, algunas de ellas de carácter alcohólico. Estos ceremoniales encuentran su mejor ámbito de representación en espacios funerarios, habiéndose detallado una amplia diversidad de rituales en los que estos recipientes jugaban diferentes roles, incluyendo su amortización intencional, encaminados a la legitimación y prestigio tanto del difunto como de su linaje (Garrido 2000; Blasco et al. 2019).

Más complejo resulta rastrear la ritualidad de estos recipientes en contextos no funerarios, en tanto estos quedan modificados o alterados por palimpsestos estratigráficos generados por los diferentes usos de las áreas de actividad o los espacios domésticos. Por lo que afecta a espacios de carácter productivo, la presencia de estos recipientes se ha relacionado con rituales propiciatorios, como sería el caso de la factoría salinera de Molino Sanchón II (Zamora), donde se documentó la rotura intencional de más de un millar de fragmentos (Delibes et al. 2016). Concentraciones similares se han observado en diferentes contextos peninsulares relacionados con áreas de actividad especializadas, tanto con la metalurgia como con el procesado de sal (Guerra et al. 2015: 178), lo que estaría denotando la voluntad de las élites sociales de ritualizar las bases económicas sobre las cuales se sustentaría su posición privilegiada, convirtiendo a la cerámica campaniforme en un auténtico bien de prestigio al considerarse como un elemento de legitimación ideológica de las relaciones de poder (De Marrais et al. 1996; Garrido 2005). No relacionada con actividades estrictamente económicas, en el Peñón de la Zorra (Villena) se documentó una amplia vajilla, compuesta por más de veinte vasijas decoradas de diferente morfología, en un ambiente que, por su registro arqueológico, no puede ser calificado como doméstico, sino que, más bien, debió estar relacionado con el control del territorio (Alba y García Atiénzar 2018).

En diferentes contextos peninsulares definidos como domésticos también se han documentado importantes concentraciones de material campaniforme, aunque rara vez con porcentajes superiores al 5-6\%. La acumulación de vasos campaniformes e, incluso, de determinados tipos decorativos en sectores concretos de asentamientos de la Estremadura portuguesa, como Zambujal, Penha Verde, Moita da Landra o Leceia (Cardoso 2014; Kunst 2017) se ha relacionado con el papel sociopolítico jugado por esos sitios, pudiendo haber servido algunos como lugares de residencia de los grupos privilegiados, inferencia que también ha quedado atestiguada en el SE -Cerro de la Virgen o Los Millares (Molina et al. 2016; 2017)- o la Meseta Camino de las Yeseras (Liesau et al. 2008)-. Por otro lado, ya hace tiempo que se apuntó la existencia de una cierta diferenciación, tanto por lo que respecta a la capacidad de los recipientes como a la sintaxis decorativa, entre los contextos domésticos y los funerarios en la Meseta central (Garrido 2000: 75), lo cual abre la posibilidad de que en los contextos de hábitat se desarrollasen prácticas diferentes a las realizadas en los ceremoniales de enterramiento.

Para el ámbito doméstico que nos ocupa en este trabajo, donde no hubieron más de tres o cuatro vasos, resulta más complejo concretar su funcionalidad o relacionarla con élites dirigentes. En cualquier caso, debió estar relacionada con las prácticas de comensalidad desarrolladas por el grupo humano que ocupó la unidad doméstica. En este sentido, la reevaluación de contextos próximos, como el del Promontori, con cerca de 300 fragmentos decorados (Ramos Fernández 1986; Ruiz 1990), permitirá ahondar en el sentido social de la vajilla campaniforme en contextos domésticos en la zona Este peninsular, donde los contextos campaniformes no denotan niveles de desigualdad social tan acusados como los advertidos en otras regiones.

\section{EL ESTUDIO DE LOS VASOS}

A pesar de la alta fragmentación del conjunto cerámico, se ha podido restituir un número mínimo de 6 vasos, predominando formas geométricas básicas derivadas de la esfera o el elipsoide, aunque nunca se ha llegado a determinar formas completas (fig. 9). El grupo morfológico menos numeroso, con tan solo un ejemplar del que se ha calculado un diámetro de 230 mm (1028-01-01), es el del casquete esférico, morfología con la que se pueden relacionar algunos de los fragmentos de borde de tipo CVS. En segundo lugar, destacan dos ejemplares de tendencia esférica (1039-02 y 1027-03) con diámetros de boca de $144 \mathrm{~mm}$ y $250 \mathrm{~mm}$. Dentro de esta morfología encontrarían acomodo algunos de los bordes cóncavos entrantes y rectos entrantes. Ambos grupos pueden ponerse en relación 


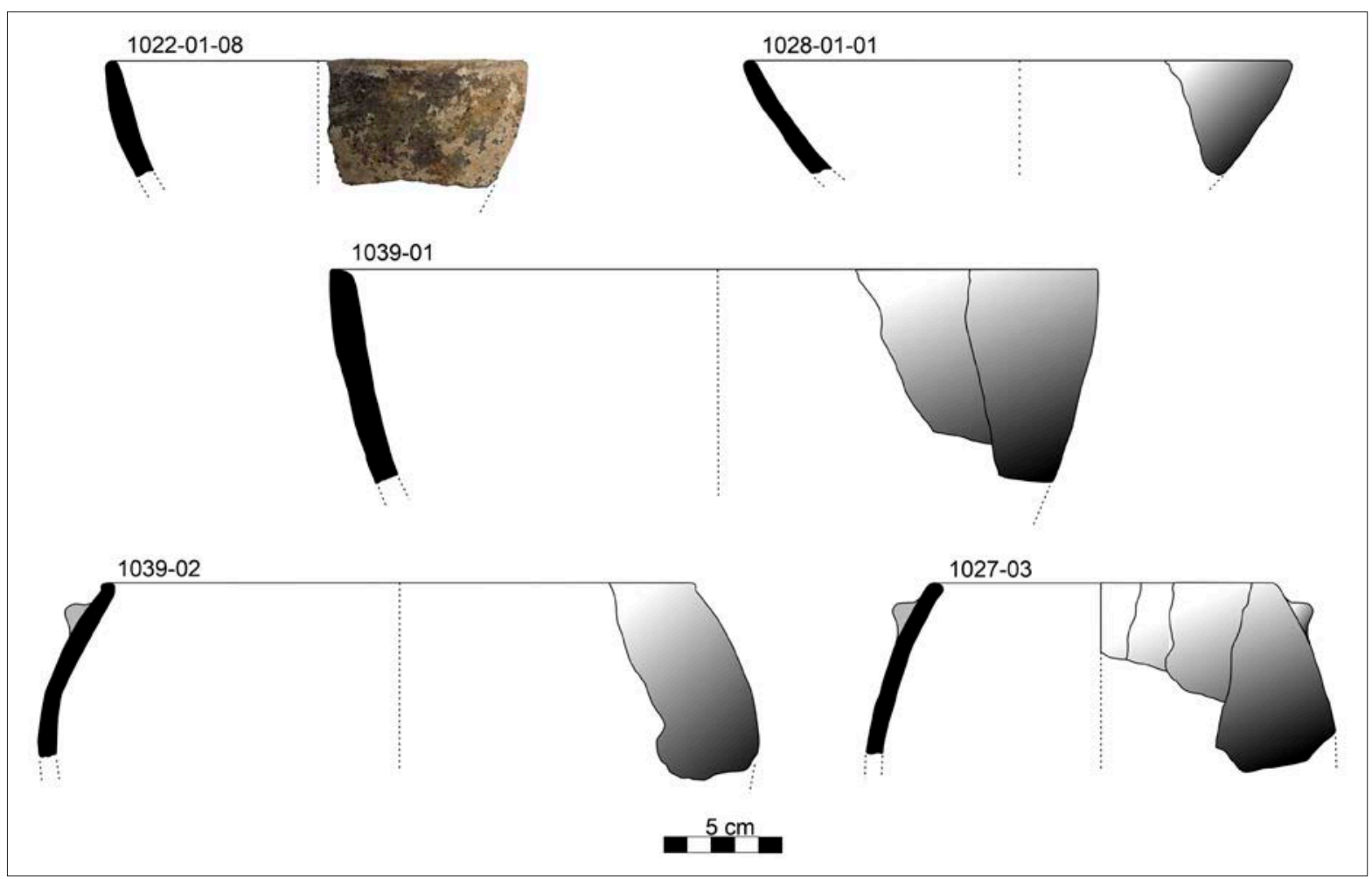

Fig. 9: Vasijas cerámicas restituibles.

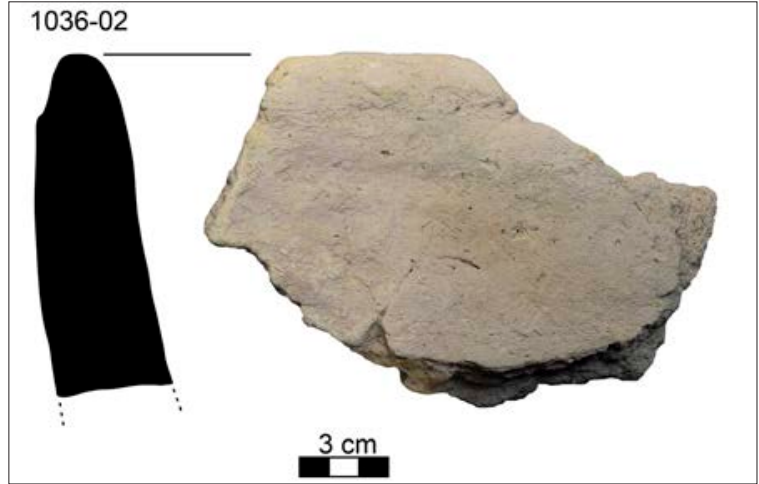

Fig. 10: Fragmento de recipiente de barro.

con vasijas de capacidad media a las que se pueden asociar diferentes actividades, desde el cocinado y transformación de alimentos hasta su uso como contenedor de algún alimento. Por último, se documentaron tres vasijas de morfología semiesférica, aunque solo de dos se pudo obtener el diámetro $-176 \mathrm{~mm}$ y $328 \mathrm{~mm}$, siendo este último el de mayor diámetro del conjunto-. Por su tamaño, podrían pertenecer a cuencos relacionados tanto con el almacenamiento como con la transformación de alimentos, dato que cobra mayor relevancia si consideramos que el vaso 1039-01 se documentó en el relleno del hogar.

Por otro lado, se documentó un fragmento de barro endurecido y secado (1036-02) con labio redondeado, borde recto y desgrasante orgánico (fig. 10). Sus dimensiones permiten relacionarlo con un recipiente de gran tamaño vinculado al nivel de ocupación de la cabaña. La presencia de recipientes de barro, posiblemente fijos, en cronologías prehistóricas resulta una constante en contextos domésticos desde, al menos, el V milenio cal BC, haciéndose más patentes a partir del IV-III milenio cal $\mathrm{BC}$, pudiendo vincularse a las diferentes actividades realizadas en la cabaña, particularmente el almacenamiento (Gómez 2006; Pastor 2017).

\section{LOS PRODUCTOS LÍTICOS}

El conjunto de piezas líticas talladas no es muy abundante, contabilizándose un total de 12 . Todas estas piezas están realizadas en sílex, siendo, en su mayor parte, 


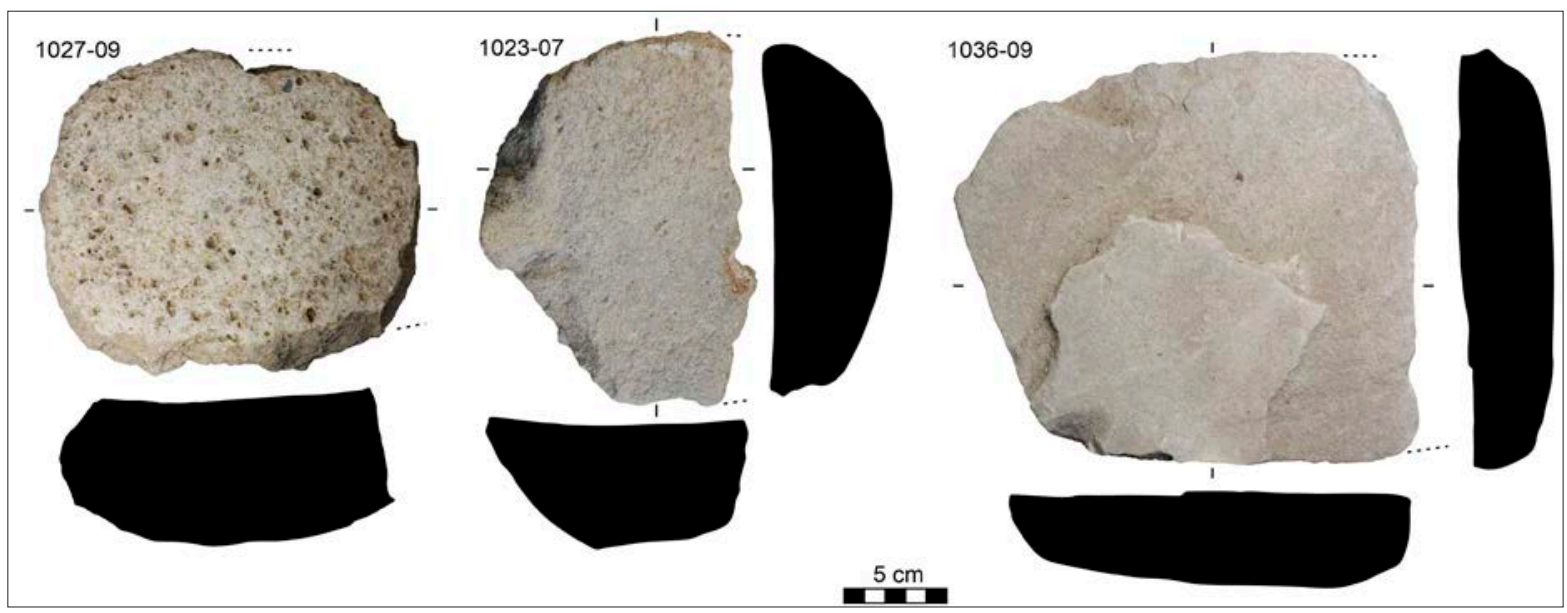

Fig. 11: Elementos macrolíticos relacionados con la molienda.

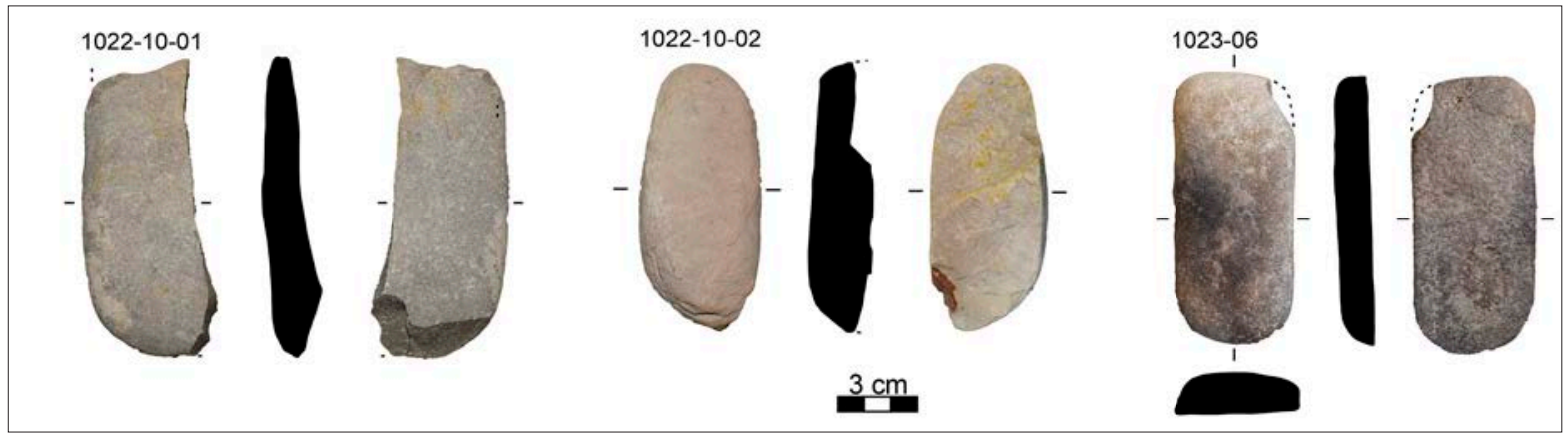

Fig. 12: Alisadores y afiladeras.

elementos indeterminados o restos informes vinculados al proceso de talla lo que, unido a lo limitado del registro y a su asociación a diferentes niveles de abandono y de derrumbe, impide realizar valoraciones objetivas sobre esta producción, así como invalida cualquier intento de establecer inferencias sobre la existencia o no de áreas de actividades concretas que sí se han podido determinar en otros asentamientos (Jover et al. 2018). En cuanto a los soportes identificados, encontramos fragmentos de lasca, algunos con retoque y señales de uso que permiten su identificación como muesca, tal vez relacionados con el trabajo de materias primas como el hueso o la madera. Si tomamos en consideración las características macroscópicas del sílex -tonalidades marrones y grisáceos-, la materia prima provendría de diferentes zonas cercanas a Elche, como la sierra de Crevillente, de Elche y de Tabayá, además de zonas próximas a Aspe (Jover 2014: 177).
El instrumental macrolítico está representado por 12 elementos repartidos por las diferentes unidades estratigráficas. El estado de conservación permite reconocer determinados tipos, entre los que destacan varios elementos de molienda, completos o fracturados, que se corresponden tanto con molinos como con molederas. En su mayor parte presentan desgastes importantes, dato que evidenciaría su dilatado uso. Dos de estos elementos aparecieron asociados al nivel de uso de la cabaña, lo que permite inferir que este tipo de actividades se pudieron realizar en su interior (fig. 11), aunque otros aparecieron en niveles de derrumbe, pudiendo interpretarlos como elementos reutilizados como material de construcción. También se documentaron otros elementos, como un alisador y dos afiladeras (fig. 12), que podrían remitir a diferentes actividades artesanales relacionadas, por ejemplo, con la cerámica y con el afilado de utensilios (Jover et al. 2012: 38). Al igual que ocurre con los elementos de 
molienda, se documentaron varias piezas informes o muy fragmentados que no pueden ser relacionadas con actividades concretas y que, por su posición estratigráfica, pudieron haber sido reutilizadas como mampuestos. En todos los casos, la materia prima está formada por rocas calizas, areniscas y micro-conglomerados, pudiendo provenir de zonas próximas como las sierras de Elche y Crevillente e, incluso, Aspe (Jover 2014: 186), vinculándose, por tanto, a afloramientos locales. Cabe destacar la aparición de un instrumento indeterminado realizado sobre roca volcánica, materia prima que podría haber sido conseguida en zonas como la isla de Tabarca o el Bajo Segura (Jover 2014: 185).

\section{ELEMENTOS DE ADORNO Y EVIDENCIAS MALA- COLÓGICAS}

Durante los trabajos de excavación se documentaron hasta 11 restos malacológicos, todos ellos asociados a especies de bivalvos, presentando cinco casos un alto grado de fragmentación, lo cual ha dificultado su identificación

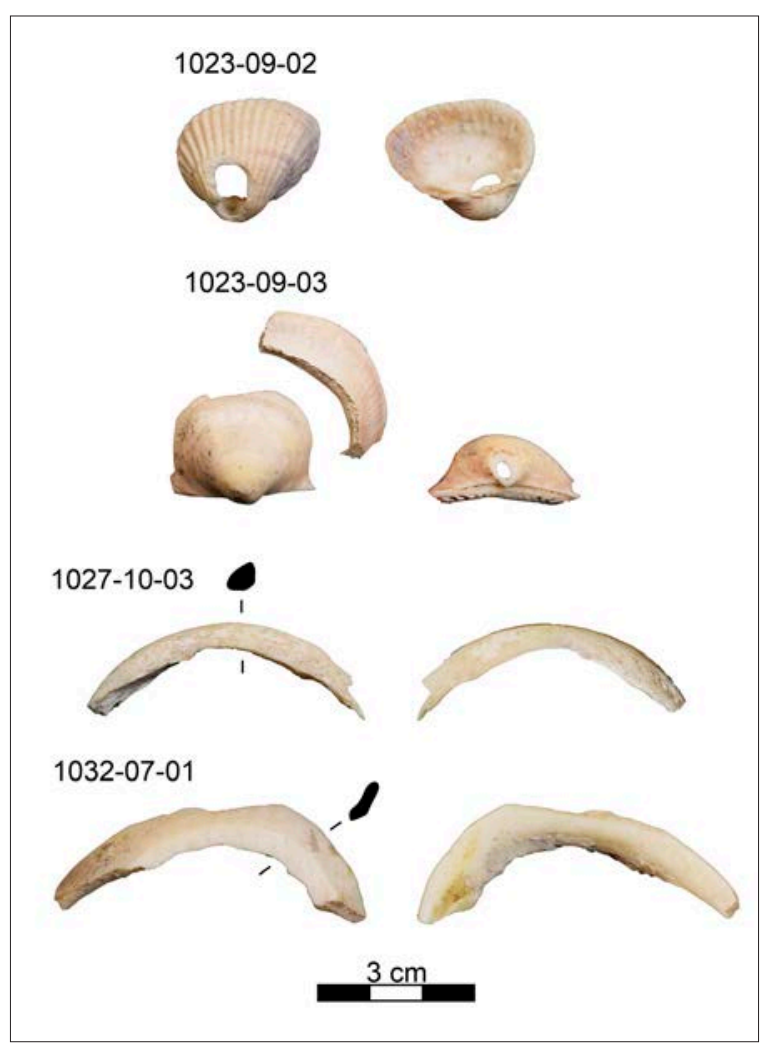

Fig. 13: Elementos de adorno sobre concha. taxonómica. Algunos de estos restos se corresponden con valvas de Glycymeris sp., sin aparentes modificaciones, rasgo que también se observa en dos conchas de Cerastoderma edule. El resto de evidencias (fig. 13) muestra particularidades significativas, pudiendo destacarse un ejemplar de Cerastoderma edule con perforación por percusión y rotación y un ejemplar fragmentado de Glycymeris sp. con perforación del natis por abrasión. Estas dos piezas encajarían en la tipología de colgantes de concha entera, que mantienen su morfología anatómica natural (Pascual Benito 1998: 129). Se recuperaron también dos fragmentos de pulseras realizados sobre el borde de concha de Glycymeris sp., presentando, al menos una de ellas, un claro pulimento. Debe señalarse que este tipo de elementos de adorno son escasos en contextos campaniformes (Pascual Benito 1998), en contraposición con lo observado en contextos neolíticos. C. Pau (2016: 858), en relación con los elementos de adornos campaniformes, aboga por la interpretación de este tipo de elementos como posibles tobilleras, sin dejar de lado su función como pulseras.

La presencia de conchas, completas o transformadas en elementos de adorno, evidenciaría una clara vinculación con la costa, pudiendo haber sido captadas directamente en zonas como la antigua Albufera d'Elx que durante el momento de ocupación de El Arsenal debió situar su álveo a poco más de $5 \mathrm{~km}$ del yacimiento. La presencia de materia prima sin modificar permite plantear que su modificación y transformación en elementos de adorno pudo haberse realizado en el propio asentamiento, pudiendo haber pasado a formar parte de posibles sistemas de intercambio entre diferentes sociedades humanas, cuestión que viene documentándose en la región desde el V milenio cal BC (Barciela et al. 2014).

\section{MATERIAL COLORANTE}

Para finalizar debemos destacar la presencia de un nódulo de buen tamaño $(129$ x 71 x $79 \mathrm{~mm})$ de material colorante, posiblemente ocre o cinabrio, en la UE 1032 -derrumbe asociado a la cabaña-. El empleo de este tipo de materia prima se reconoce en diferentes contextos arqueológicos, documentándose de manera constante desde el Neolítico (López Padilla et al. 2012: 273-274) y asociándose al adorno personal, bien sobre las vestimentas o directamente sobre la piel, observándose incluso en tumbas y enterramientos varios (Cortell 2016: 190). La presencia de minerales colorantes en contextos campaniformes 
resulta una constante, pudiéndose destacar los recientes hallazgos de las tumbas de Humanejos en Parla (Madrid) (Garrido et al. 2019), en diferentes fosas de La Salmedina, en el distrito de Vallecas (Madrid) (Berzosa y Flores 2005) o en los restos humanos descubiertos en la Magdalena I, en Alcalá de Henares (Madrid) (Cabrera et al. 2012).

\section{DEL ESPACIO DOMÉSTICO AL ESPACIO SOCIAL: HÁBITAT Y TERRITORIO DURANTE LA $2^{\mathrm{a}}$ MITAD DEL III MILENIO cal BC}

Con lo expuesto, y aunque con las limitaciones impuestas por las características de la intervención y el estado de conservación del registro, creemos que podemos aproximarnos a la realidad histórica que se conformó en el Bajo Vinalopó durante buena parte de la segunda mitad del III milenio cal BC, organizando esta narración a partir de la concatenación de diferentes unidades de observación, desde los artefactos, estructuras y actividades documentadas hasta el territorio en el que se enmarca el asentamiento.

\section{ARTEFACTOS, ESPACIOS DOMÉSTICOS Y ÁREAS DE ACTIVIDADES}

La distribución espacial de los artefactos, así como su presencia a lo largo de la secuencia cronoestratigráfica, permiten profundizar en los contextos de uso, así como en su evolución. En este sentido, debemos indicar que no se observan diferencias reseñables en cuanto a la representación porcentual de los diferentes tipos a lo largo de las dos fases identificadas, así como tampoco en lo referido a otros aspectos, como podría ser las decoraciones cerámicas. Si circunscribimos el análisis sobre los artefactos, si bien el número registrado no es muy numeroso si se compara con contextos similares, podemos realizar diferentes inferencias sobre el uso de las diferentes partes que conforman el ambiente doméstico.

En primer lugar, y a partir del estudio morfotipológico de ciertos fragmentos cerámicos, además de los 6 vasos restituibles, el repertorio recuperado informa sobre una vajilla de diferente tamaño que se relaciona tanto con el consumo individual como con el preparado y almacenamiento de alimentos. El hecho que varios de estos fragmentos aparezcan en contextos primarios, asociados a estructuras internas de la cabaña, aunque posiblemente aminorados por el proceso de abandono, permite inferir que buena parte de las actividades mencionadas se desarrollaban en su interior. En este sentido, cabe destacar la presencia de un gran recipiente de barro que podemos relacionar con actividades de almacenamiento, así como una vasija de tamaño medio asociado al hogar. El instrumental macrolítico, definido por la presencia tanto de elementos de molienda - manos de molino y fragmentos de molino- como de afiladeras y un alisador, ofrece información de algunas de las actividades que pudieron haberse realizado en el interior la cabaña. Por último, debemos destacar la existencia de algunos elementos de adorno -brazaletes, colgantes, etc.-, así como valvas completas que pudieran interpretarse como materia prima en reserva, en contextos claramente domésticos.

\section{ESTRUCTURAS DOMÉSTICAS Y BASES ORGANI- ZATIVAS}

En segundo lugar, y siguiendo con la concatenación de unidades de observación, las estructuras domésticas deben relacionarse, a tenor de lo documentado en 2010, pero también en intervenciones realizadas posteriormente, con un asentamiento al aire libre, aparentemente no delimitado, situado en una de las terrazas del río Vinalopó.

Para la Prehistoria reciente, especialmente durante el Neolítico y Calcolítico, resulta complejo concretar las características de los espacios domésticos habida cuenta del empleo preferente del barro como material arquitectónico (Pastor 2017). Sin embargo, en las últimas décadas se han documentado buenos referentes de este tipo de arquitectura doméstica. De entre ellos, aunque de una cronología sensiblemente anterior $(4270 \pm 110 \mathrm{BP} /$ 3330-2505 cal BC 20), destaca el yacimiento de La Torreta-El Monastil (Elda), donde se documentó un fondo de cabaña -Estructura 1 (Jover et al. 2010)- con unas dimensiones máximas de 3,24 x 1,53 m y planta ovalada. Al igual que sucede en El Arsenal, se documentaron pellas de barro que confirman el empleo de este material como elemento constructivo. Otro caso similar lo encontramos en la Illeta dels Banyets (El Campello), donde se documentaron diversas cabañas prehistóricas, la mayoría mal conservadas. La cabaña $\mathrm{n}^{\circ} 3$, fechada en el Calcolítico

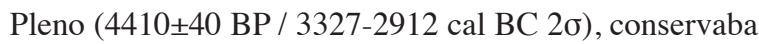
una planta semioval semi-excavada de $7 \mathrm{~m}$ de diámetro exterior delimitada por un zócalo realizado a base de lajas de costra calcárea y que empleaba el barro tanto para el propio zócalo como para las paredes (Soler y Belmonte 
2006). También asociados a contextos calcolíticos, se han descrito diferentes tipos de unidades domésticas en La Vital, en Gandía, predominando las estructuras de hábitat rehundidas, algunas de ellas con hogares y otros elementos en su interior (Gómez et al. 2011), o la Ereta del Pedregal, en la Canal de Navarrés (Juan-Cabanilles 1990), donde, en su fase II, se han descrito varios muros con las caras delimitadas mediante lajas verticales y un relleno irregular de piedras y tierra y que parecen corresponder a diferentes unidades habitacionales con sucesivos pavimentos de barro rubefactado.

Esta imagen se asemeja, aunque con matices, a lo observado en el SE durante el Calcolítico, momento en el cual empiezan a proliferar cabañas con plantas elípticas y/o circulares construidas con mampostería según se observa en yacimientos como El Malagón en Cúllar-Baza (Arribas et al. 1978), el Cerro de la Virgen de Orce (Schüle y Pellicer 1966; Sáez y Schüle 1985), Los Millares en Santa Fé de Mondújar (Molina y Cámara 2005) o el Cabezo del Plomo en Mazarrón (Muñoz 1993). Esta novedad arquitectónica se documenta desde finales del IV y, sobre todo, el III milenio cal BC, como bien han puesto de manifiesto las excavaciones realizadas en Fuente de Isso (García Atiénzar 2010), El Prado (Jover et al. 2012) y Vilches en Hellín (García Atiénzar et al. 2016; García Atiénzar y Busquier 2020), por citar solo algunos ejemplos del ámbito del E peninsular.

El referente cronológicamente más próximo lo encontramos en Les Moreres (Crevillente), un poblado en altura delimitado por una muralla en cuyo interior se documentaron, al menos, tres fases constructivas, todas ellas asociadas al Campaniforme. Las más antiguas, que corresponden a los estratos IIa3-IIa4 y IIa5-IIa6, se asocian a cabañas ovales y circulares con diámetros que oscilan entre los 3 y los $5 \mathrm{~m}$ definidos por zócalos cimentados con piedras y barro (González Prats y Ruiz Segura 1991-1992). El estrato IIa2, asociado a los momentos finales, se caracteriza por cabañas de plantas ovaladas o subcirculares que se construyen con paredes de barro amasado con piedras menudas que recubre el perímetro de postes de madera que configura la planta, cuyo alzado se realizaría mediante un techado cónico (González y Ruiz 1991-1992: 19), en la que destaca una gran vivienda con un eje entre los 6-7 $\mathrm{m}$.

En Elche, la documentación de estructuras de hábitat se relaciona con el Neolítico final, debiendo señalarse el asentamiento de Figuera Reona, situado en la margen derecha del Vinalopó, donde se registraron un total de ocho estructuras con diámetros entre 1,20 y 2 m que fueron interpretadas inicialmente como fondos de cabaña circulares construidos con un zócalo de piedras, utilizando adobes y ramajes para sus muros y techumbre (Ramos Folqués 1989). En el sitio campaniforme del Promontori de l'Aigua Dolça i Salà, en el denominado Estrato C (Ramos Fernández 1981), se pudo identificar un fondo de cabaña con un diámetro de 2,30 $\mathrm{m}$ al cual se asociaban restos constructivos - pellas de barro con caras alisadas y con huellas de ramaje- que permitieron su interpretación como construcción de hábitat.

Buena parte de los contextos enumerados, situados la mayor parte en el III milenio cal BC, muestran la paulatina transición desde una arquitectura en la que predominaba el barro como principal material constructivo, hacia otra en la que la mampostería empieza a tener mayor presencia, aunque el empleo de los morteros de tierra siempre seguirá presente, si bien limitado a parte de los alzados y, sobre todo, a las techumbres. El caso de El Arsenal puede suponer un buen ejemplo de esta transformación, observándose como en la fase más antigua el empleo de la piedra debió estar circunscrito al zócalo, predominando el barro y elementos vegetales -debe recordarse el amplio número de fragmentos de barro con improntas asociados a la fase de abandono de este primer momento-, mientras que en el momento de ocupación más reciente aparece un alineamiento de muro de mampostería y un amplio nivel de derrumbe compuesto, fundamentalmente, por mampuestos.

Si pasamos a analizar el interior de los espacios domésticos, el hogar ocupa un lugar central, distribuyéndose a su alrededor el resto de estructuras -cubetas, bancos o plataformas-. Este tipo de estructuras, que aparecen con similar disposición y morfología en el interior de cabañas en yacimientos como Fuente de Isso, Vilches, La Vital, El Malagón o Les Moreres, entre otros, sirven como eje de articulación de las actividades domésticas.

A partir de los artefactos, pero también de las estructuras domésticas descritas, así como de las vinculaciones entre estas dos unidades de observación, podemos inferir la existencia de una unidad doméstica que se encontraría, en realidad, integrada dentro de un asentamiento mayor -aldea-, constituido, a su vez, por un grupo humano con un modo de vida campesino. Este modo de vida estuvo orientado a la producción de alimentos de base cerealista, posibilidad inferida a partir de la información aportada de manera indirecta por los artefactos recuperados, sin desdeñar la actividad ganadera, solo inferida a partir de unos pocos restos de fauna cuya identificación taxonómica 
se revela compleja por el estado de conservación. Junto a la agricultura y ganadería, es importante destacar también la clara vinculación del yacimiento con el territorio circundante en tanto este sirvió de área de explotación de diferentes recursos bióticos y abióticos -sílex, calizas, areniscas, malacofauna, arcillas, etc.- necesarios para el desarrollo de actividades de producción y reproducción de la sociedad.

Este patrón de asentamiento estaría próximo al concepto de aldea abierta, de la cual resulta un buen ejemplo La Torreta-El Monastil (Jover 2010), pero también otros sitios enumerados para el Vinalopó, el Segura o el Serpis. Para el caso del yacimiento de Elda se ha propuesto una interpretación como un asentamiento de pequeño tamaño, de menos de 1 ha, compuesto por diversas cabañas y otras estructuras situadas en sus proximidades relacionadas con actividades de almacenamiento y producción, entre otras. Este modelo contrasta con el ofrecido por el contemporáneo sitio de Les Moreres, para la cual se puede hablar de una aldea integrada y fortificada que ocuparía una extensión menor, posiblemente en torno a las 0,5 ha. Estas diferencias deben ser explicadas desde la pertenencia de estos dos sitios a proyectos políticos y económicos diferentes, estando el yacimiento de Crevillente integrado dentro del ámbito de Los Millares y el Calcolítico del SE peninsular.

\section{EL ESPACIO SOCIAL Y RELACIONES SOCIO- POLÍTICAS CON EL ENTORNO}

El Camp d'Elx, y el Bajo Vinalopó en general, asiste a un importante desarrollo del poblamiento humano durante buena parte del III milenio cal BC, siendo buen reflejo de ello la aparición de diferentes asentamientos al aire libre (fig. 14), sin que por el momento podamos concretar su total sincronía entre ellos. Centrándonos en el Campaniforme, hace ya varias décadas que se apuntó la existencia de este tipo decorativo en La Alcudia (Bernabeu 1984: 26), concretamente un cuenco globular con decoración incisa similar a la vista en El Arsenal. En la Figuera Reona, asentamiento de algo más de $14.000 \mathrm{~m}^{2} \mathrm{si}$ incluimos los hallazgos de las partidas de La Rata y La Reja, cuya ocupación debió iniciarse en el Neolítico final si atendemos a su cultura material (Ramos Folqués 1989: 15), también se documentó un único fragmento de cerámica decorada. En este caso, la extensión mostrada por sus evidencias serían un buen síntoma de la perduración e intensificación del poblamiento durante el III milenio, hecho también evidenciado por la proliferación de concentraciones de silos, como la señalada en Galanet (Jover et al. 2014), pero también en otros puntos del Bajo Vinalopó (Soler et al. 2014). El yacimiento campaniforme más significado para el Camp d'Elx es, sin duda, el
Fig. 14: Localización de los yacimientos calcolíticos y campaniformes en el entorno del Bajo Vinalopó y Bajo Segura. 1. Tabayá; 2. El Castellar; 3. Promontori; 4. La Rata; 5. Figuera Reona; 6. Galanet; 7. La Alcudia; 8. Playa del Carabassí; 9. Cova de les Aranyes del Carabassí; 10. Les Moreres; 11. Canyada Joana; 12. Cabezo de Redován; 13. Bancalico de los Moros; 14. Espeñetas.

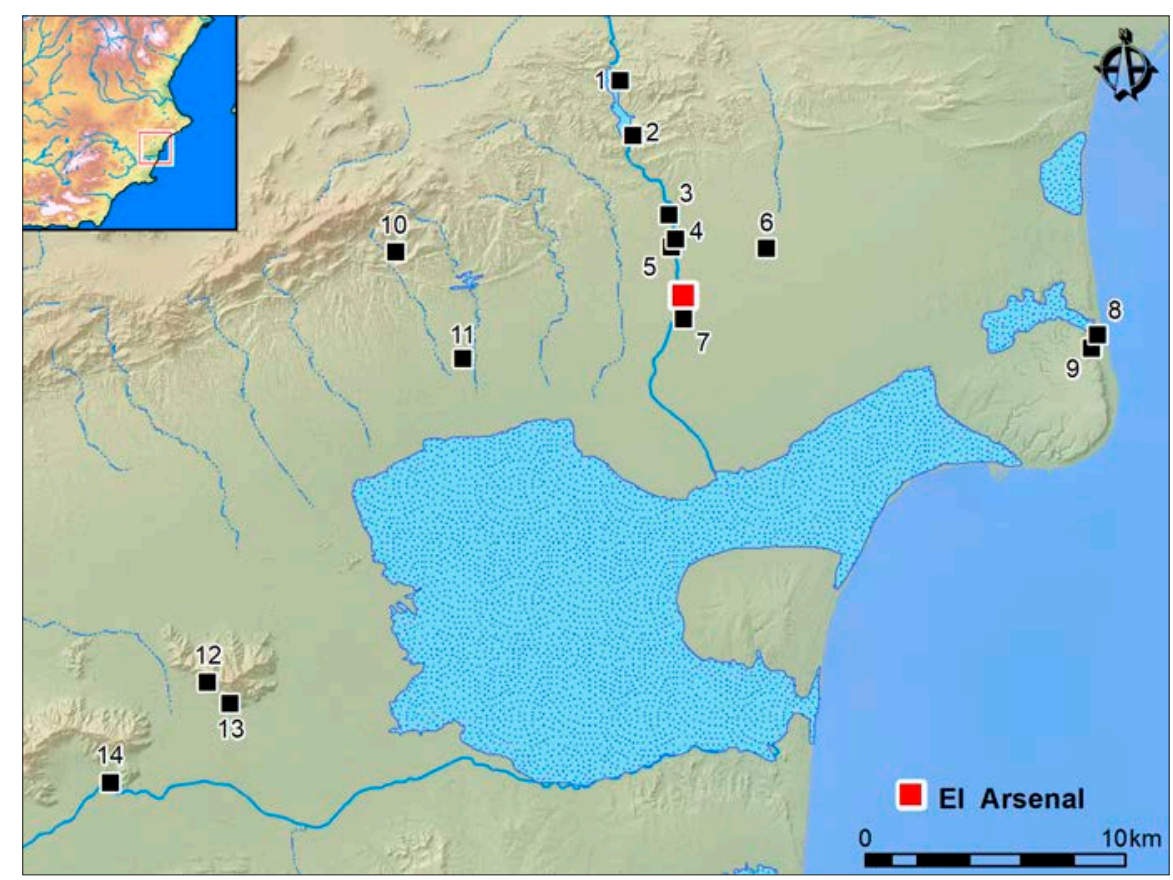


Promontori de 1'Aigua Dolça i Salà que, según su excavador (Ramos Fernández 1981), iniciaría su secuencia en el Neolítico final y perduraría hasta el Bronce antiguo, propuesta esta última que fue matizada posteriormente (López Padilla 2006), confirmándose una ocupación plenamente calcolítica. En el Estrato B, y sobre un pavimento de arenisca y arcilla, se documentó una singular concentración de vasijas campaniformes (Ramos Fernández 1981; 1983; 1984a; 1984b) asociada a una bolsada de cenizas (Ramos Fernández 1981: 202) interpretada como un fondo de cabaña.

Las evidencias campaniformes no se limitan a las proximidades del cauce del Vinalopó, sino que también se ha determinado en la costa, concretamente en el entorno de la Playa del Carabassí (Elche), espacio ocupado desde el Neolítico final en relación con la captación y consumo de productos malacológicos (Soler y López 2000-2001; Soler et al. 2014), y en las estribaciones que delimitan por el $\mathrm{N}$ la comarca natural del Bajo Vinalopó, concretamente en el yacimiento de El Castellar donde, si bien no se han documentado materiales cerámicos campaniformes, sí se tiene constancia de material lítico, especialmente un par de puñales con retoque bifacial elaborados sobre sílex tabular (Ramos Folqués 1989; López Padilla 2010) que han sido relacionados con este momento (Juan-Cabanilles et al. 2006).

$\mathrm{El}$ volumen de yacimientos con una secuencia plena o parcialmente campaniforme en esta zona del Bajo Vinalopó permite plantear, a modo de hipótesis, la existencia de varias comunidades, probablemente con un limitado peso demográfico, que ocuparían las mejores tierras ubicadas en torno al cauce. A diferencia de lo que se observa en otros yacimientos, especialmente los vinculados al grupo de Los Millares, del cual Les Moreres pudo ser la evidencia más septentrional, no podemos hablar de una fijación permanente de las comunidades humanas ya que las unidades domésticas se desplazarían por el territorio conforme sus estructuras de hábitat quedaban amortizadas, aunque, como ponen de manifiesto El Arsenal o la amplia secuencia mostrada por los materiales de la Figuera Reona, en ocasiones se observan reocupaciones, perduraciones y reconstrucciones sobre los mismos espacios. Esta consolidación cabría explicarla desde el crecimiento demográfico de las comunidades campesinas asentadas en la zona desde, al menos, el V milenio cal $\mathrm{BC}$, generándose nuevas unidades domésticas que se ubicaría en las proximidades de las anteriores, pero siempre cerca de cauces y de las mejores tierras.
Al S de este territorio, en torno a la desembocadura del Segura, durante el Campaniforme se documentan también un buen número de asentamientos, aunque esta vez ubicados en altura. Sitios como Espeñetas (Orihue1a), Bancalico de Los Moros (Redován) y, especialmente, Les Moreres (Crevillente), donde se constata por primera vez la presencia de un sistema de fortificación en la zona, deben explicarse desde la dinámica poblacional e histórica del SE entendida a partir de la extensión del sistema sociopolítico del grupo de Los Millares hasta las últimas y más orientales vetas cupríferas del sistema bético situadas, precisamente, en torno a la sierra de Crevillente (Jover y García 2014: 264; Jover et al. 2019).

La aparición de estos enclaves en altura tendrá su correlación en el ámbito del Vinalopó, donde también se empezarán a constatar sitios en altura -El Castellar en Elche (López Padilla 2010), El Tabayá en Aspe (Hernández 2009; Hernández et al. 2019), El Monastil en Elda o el Peñón de la Zorra y el Puntal de los Carniceros en Villena (García Atiénzar 2016), etc.-, aunque estos serán de menor entidad que los observados en el Segura y siempre en relación con el control del movimiento a través del cauce. La constatación de este nuevo tipo de asentamiento en el Vinalopó no supuso, según evidencian las dataciones disponibles (García Atiénzar 2017), el abandono de los asentamientos al aire libre, generándose durante algunos siglos una clara dualidad, habitándose tanto el llano -cerca de ríos y sus terrazas- como lugares en altura -cabezos, peñones, etc.-, dualidad que puede relacionarse con los cambios socioeconómicos que se dan a mediados del III milenio cal BC, con la clara influencia de Millares sobre este espacio y con la necesidad de estas comunidades de controlar no solo las zonas de producción, sino también las rutas de intercambio que en este momento conocen una importante intensificación. En cualquier caso, esta dualidad se truncará en torno al 2200 cal BC, momento en el cual se abandonan los asentamientos campaniformes del Bajo Segura, creándose ahora otros nuevos de grandes dimensiones, como San Antón (Orihuela) o Laderas del Castillo (Callosa del Segura), que se sitúan en lugares con un mayor control sobre el territorio, lo que denota un cambio en las estrategias de apropiación del espacio social que se desarrollará con claridad a partir de época argárica. Esta transformación coincide, asimismo, con el abandono de los sitios campaniformes en llano ubicados en el Vinalopó y la fundación (o reordenación) de enclaves de mediano tamaño, como Tabayá (Aspe), Pic 
de les Moreres (Crevillente) o Illeta dels Banyets (El Campello), que evidencian la inclusión de este espacio en el territorio argárico, dibujando, además, su frontera septentrional (Jover y López 1997).

\section{NOTAS}

1. Queremos agradecer a Eduardo López Seguí, gerente de la empresa Alebus Patrimonio Histórico S.L.U. y director de la intervención arqueológica, la autorización y las facilidades prestadas para el estudio de la información y materiales recuperados durante la excavación. Este trabajo ha sido realizado dentro del proyecto HAR 2016-76586-P Espacios sociales y espacios de frontera durante el Calcolítico y la Edad del Bronce en el este de la península Ibérica, financiado por el Ministerio de Economía y Competitividad del Gobierno de España.

2. Durante los trabajos de excavación, se recuperaron varios restos de naturaleza antracológica y arqueozoológica, además de varias muestras de sedimento destinadas a flotación y análisis palinológico. Lamentablemente, estas evidencias no pudieron ser estudiadas.

\section{BIBLIOGRAFÍA}

ALBA, M. (2016): La vajilla campaniforme en Villena, Villena.

ALBA, M.; GARCÍA ATIÉNZAR, G. (2018): Beaker pottery in the Peñón de la Zorra (Alicante, Spain): Change and emergence of social complexity between the Neolithic and the Bronze Age, Journal of Neolithic Archaeology 20: 59-76. DOI: https://doi.org/10.12766/jna.2018S.4

ARRIBAS, A.; MOLINA GONZÁLEZ, F.; DE LA TORRE, F.; NÁJERA, T.; SÁEZ, L. (1978): El poblado de la Edad del Cobre de El Malagón (Cúllar-Baza, Granada). Campaña de 1975, CPUG 3, 67-116, <https://revistaseug.ugr.es/index. php/cpag/article/view/732>.

BARCIELA, V. (2014a): Galanet: el estudio de la malacofauna, $E l$ Neolítico en el Bajo Vinalopó (Alicante, España) (F. J. Jover, P. Torregrosa, G. García Atiénzar, coords.), Oxford, 195-201.

BARCIELA, V. (2014b). Galanet: los adornos personales, El Neolítico en el Bajo Vinalopó (Alicante, España) (F. J. Jover, P. Torregrosa, G. García Atiénzar, coords.), Oxford, 191-194.

BARCIELA, V.; GARCÍA ATIÉNZAR, G.; LÓPEZ SEGUÍ, E. J. (2014): El yacimiento prehistórico de los Limoneros II (Elche), El Neolítico en el Bajo Vinalopó (Alicante, España) (F. J. Jover, P. Torregrosa, G. García Atiénzar, coords.), Oxford, 195-201.

BERNABEU, J. (1984): El Vaso Campaniforme en el País Valenciano, Trabajos Varios. S.I.P. 80, València.
BERZOSA, O. R.; FLORES, M. (2005): El conjunto funerario campaniforme del Vertedero de "La Salmedina" (Distrito Villa de Vallecas, Madrid), El Campaniforme en la Península Ibérica y su contexto europeo (M. A. Rojo, R. Garrido, I. García, coords.), Valladolid, 481-494.

BLASCO, C.; LIESAU, C.; DÍAZ, P. (2019): El registro funerario campaniforme de la Región de Madrid como reflejo de una sociedad plural y compleja, ; Un brindis por el príncipe! El vaso campaniforme en el interior de la Península Ibérica (2500-2000 A.C.) (G. Delibes, E. Guerra, coords.), Madrid, tomo $1,247-277$.

BRADLEY, R. (2005): Ritual and Domestic Life in Prehistoric Europe, London.

CABRERA, C.; GALERA, V.; HERAS, C. M. (2012): El Campaniforme en la submeseta sur: Estudio antropológico de los restos arqueológicos de la Magdalena I (Alcalá de Henares), Actas de las novenas jornadas de Patrimonio Arqueológico en la Comunidad de Madrid, Madrid, 127-136.

CARDOSO, J. L. (2014): Absolute chronology of the Beaker phenomenon North of the Tagus estuary: demographic and social implications, TP 71 (1), 56-75.

DOI: http://dx.doi.org/10.3989/tp.2014.12124

CORTELL, A. (2016): El ocre en la Prehistoria: entre la funcionalidad y el simbolismo, APL 31, 187-211, <http://mupreva. org/pub/938/es>.

DELIBES, G.; GUERRA, E.; ABARQUERO, F. J. (2016): Rituales campaniformes en contextos no funerarios: la factoría salinera de Molino Sanchón II (Villafáfila, Zamora), ARPI. Arqueología y Prehistoria del Interior Peninsular 04 (Extra), 286-297

DEMARRAIS, E.; CASTILLO, L. J.; EARLE, T. (1996): Ideology, Materialization, and Power Strategies, Current Anthropology 37, 15-31, <http://www.jstor.org/stable/2744153>.

FERRER, C. (2010): El medio físico de la Vega Baja y el litoral de Guardamar. La génesis cultural de un paisaje, Guardamar del Segura, Arqueología y Museo (A. García Menarguez, com.), Alicante, 32-45.

GARCÍA ATIÉNZAR, G. (2010): El yacimiento de Fuente de Isso (Hellín) y el poblamiento neolítico en la provincia de Albacete, Albacete.

GARCÍA ATIÉNZAR, G. (2016): El Peñón de la Zorra (Villena, Alicante) y la caracterización del Campaniforme (24002100 cal AC) en el Alto Vinalopó, Del Neolític a l'Edad del Bronze en el Mediterrani occidental. Estudis en homenatge a Bernat Martí Oliver (H. Bonet Rosado, coord.), Trabajos Varios. S.I.P. 119, València, 365-377, <http://mupreva.org/ pub/914/va>.

GARCÍA ATIÉNZAR, G. (2017): La secuencia crono-cultural del yacimiento de Peñón de la Zorra (Villena, Alicante), IberCrono 2016. Cronometrías para la Historia de la Península Ibérica. Actas del Congreso de Cronometrías para la Historia de la Península Ibérica, Barcelona, Spain, September 
17-19, 2016 (J. A. Barceló, I. Bogdanovic, B. Morell, eds.), Barcelona, 128-142, <http://ceur-ws.org/Vol-2024/IberCrono_11.pdf>.

GARCÍA ATIÉNZAR, G.; BARCIELA, V.; MARTÍNEZ AMORÓS, S.; JOVER, F. J.; MOLINA, F. J.; TORMO, C.; PASTOR, M.; DEL PINO, M.; DE MIGUEL, M. P.; LÓPEZ SEGUÍ, E.; TORREGROSA, P.; FERRER, C.; PÉREZ JORDÀ, G.; CARRIÓN MARCO, Y.; LÓPEZ SÁEZ, J. A.; SIRVENT, L. M. (2020): El asentamiento neolítico de Limoneros (Elche, Alicante), Complutum 31 (1), 25-48. DOI: https://doi.org/10.5209/cmpl.71648

GARCÍA ATIÉNZAR, G.; BUSQUIER, J. D. (2020): El poblado calcolítico de Vilches IV (Torre Uchea, Hellín. Albacete). Un asentamiento del III milenio a.C. en la Submeseta sur, Alicante.

GARCÍA ATIÉNZAR, G.; BUSQUIER, J. D.; MATAIX, J. J.; CANIZARES, F.; DOMENE, P.; CARRIÓN, Y.; TORMO, C.; PÉREZ JORDÀ, G.; JOVER, F. J.; LÓPEZ PADILLA, J. A.; BARCIELA, V.; SORIANO, I. (2016): El poblado de Vilches IV: Un asentamiento calcolítico en altura en el Campo de Hellín (Albacete), Actas de la I Reunión Científica de Arqueología de Albacete (B. Gamo, R. Sanz Gamo, coords.), Albacete, 313-329.

GARRIDO, R. (2000): El Campaniforme en La Meseta Central de la Península Ibérica (c. 2500-2000 AC.), B.A.R.-I.S. 892, Oxford.

GARRIDO, R. (2005): El laberinto campaniforme: breve historia de un reto intelectual, El Campaniforme en la Península Ibérica y su contexto europeo (M. A. Rojo; R. Garrido; I. García, eds.), Valladolid, 29-60.

GARRIDO, R. (2012-2013): De la cocina y sus ingredientes a la mesa y sus rituales. Desde los orígenes hasta las tradiciones populares en la Península Ibérica, Boletín Asociación Española de Amigos de la Arqueología 47, 47-59

GARRIDO, R.; FLORES, R.; HERRERO, A. M. (2019): Las sepulturas campaniformes de Humanejos (Parla, Madrid), Madrid.

GÓMEZ, M. (2006): Estudio de los fragmentos de barro cocido en el yacimiento de la "Illeta dels Banyets" (El Campello, Alicante), La ocupación prehistórica de la Illeta dels Banyets (El Campello, Alicante) (J. A. Soler Díaz, coord.), Alicante, 271-280.

GÓMEZ, M.; PÉREZ, G.; CARRIÓN, Y. (2011): El espacio de la ocupación prehistórica, La Vital (Gandía, Valencia). Vida y muerte en la desembocadura del Serpis durante el III y el I milenio A.C. (G. Pérez; J. Bernabeu; Y. Carrión; O. García; L1. Molina; M. Gómez eds.), Trabajos Varios. S.I.P. 113, València, 53-82.

GONZÁLEZ PRATS, A.; RUIZ SEGURA, E. (1991-1992): Nuevos datos sobre el poblado calcolítico de Les Moreres, Crevillente (Alicante). (Campañas 1988-1993), Anales de Prehistoria y Arqueología 7-8, 17-20, <https://revistas.um.es/ apa/article/view/64331/62001>.
GUERRA, E.; ABARQUERO, F. J.; DELIBES, G.; PALOMINO, A. L.; DEL VAL, J. (2015): Bell Beaker pottery as a symbolic marker of property rights: the case of the salt production centre of Molino Sanchón II, Zamora, Spain, The Bell Beaker transition in Europe. Mobility and local evolution during the $3 r d$ millennium BC (M. P. Prieto, L. Salanova, eds.), Oxford, 169-180.

GUERRA, E.; DELIBES, G: (2019): La cerámica campaniforme Ciempozuelos, una vajilla al servicio de la liturgia, ; Un brindis por el príncipe! El vaso campaniforme en el interior de la Península Ibérica (2500-2000 A.C.), tomo 1 (G. Delibes, E. Guerra, coords.), Madrid, 223-241

HEATON, T.; BLAAUW, M.; BLACKWELL, P.; BRONK RAMSEY, C.; REIMER, P.; SCOTT, E. (2020): the IntCal20 approach to radiocarbon calibration curve construction: a new methodology using bayesian splines and errors-invariables, Radiocarbon 1-43. DOI: http://dx.doi.org/10.1017/RDC.2020.46

HERNÁNDEZ PÉREZ, M. S. (2009): Entre el Medio y el Bajo Vinalopó. Excavaciones arqueológicas en el Tabayá (Aspe, Alicante) 1987-1991, En los confines del Argar. Una cultura de la Edad del Bronce en Alicante (M. S. Hernández, J. A. Soler, J. A. López Padilla, eds.), Alicante, 160-169.

HERNÁNDEZ PÉREZ, M. S.; LÓPEZ PADILLA, J. A.; JOVER; F. J. (2019): Estratigrafía y radiocarbono: la tumba 1 y la cronología de la ocupación argárica del Tabayá (Aspe, Alicante), Spal 28 (1), 35-56.

DOI: https://doi.org/10.12795/spal.2019.i28.02

IBARRA, P. (1926): Elche. Materiales para su Historia, Cuenca.

JOVER, F. J. (coord.) (2010): La Torreta-El Monastil (Elda, Alicante) del IV al III milenio AC en la cuenca del río Vinalopó, Alicante.

JOVER, F. J. (2014): El instrumental lítico de Galanet, El Neolítico en el Bajo Vinalopó (Alicante, España) (F. J. Jover, P. Torregrosa, G. García Atiénzar, coords.), Oxford, 175-189.

JOVER, F. J.; ESQUEMBRE, M. A.; SOLER GARCÍA, M. D.; POVEDA, A. M.; TORREGROSA, P.; ORTEGA, J. R. (2010): Los trabajos de excavación en La Torreta-El Monastil y la Casa Colorá, La Torreta-El Monastil (Elda, Alicante): del IV al III milenio AC en la cuenca del río Vinalopó (F. J. Jover, coord.), Alicante, 43-60.

JOVER, F. J.; GARCÍA ATIÉNZAR, G. (2014): Del VI al III milenio cal BC: la configuración de nuevos espacios sociales en el valle del Vinalopó, El Neolítico en el Bajo Vinalopó (Alicante, España) (F. J. Jover, P. Torregrosa, G. García Atiénzar, coords.), Oxford, 253-265.

JOVER, F. J .; GARCIA ATIÉNZAR, G.; MORATALLA, J.; SEGURA, G.; BIETE, C.; TORMO, C.; MARTÍNEZ MONLEÓN, S. (2012): Continuidad residencial e intensificación productiva durante la primera mitad del III milenio cal BC en el Levante de la Península Ibérica: Las aportaciones 
del asentamiento de El Prado (Jumilla, Murcia), Revista Atlántica-Mediterránea de Prehistoria y Arqueología Social 14, 15-54, <https://revistas.uca.es/index.php/rampas/ article/view/2201>.

JOVER, F. J.; LÓPEZ PADILLA, J. A. (1997): Arqueología de la muerte. Prácticas funerarias en los límites de El Argar, Alicante.

JOVER, F. J.; LÓPEZ PADILLA, J. A.; GARCÍA ATIÉNZAR, G. (2019): Territory, settlements and households: Chalcolithic and Bronze Age in the Eastern Iberian Peninsula, Late Neolithic and Early Bronze Age Settlement Archaeology (H. Meller, S. Firederich, M. KüBner, H. Stäuble, R. Risch, eds.), Halle, 1003-1027.

JOVER, F. J.; MORALES, F.; GARCÍA ATIÉNZAR, G. (2018): La producción lítica tallada del asentamiento en altura del III milenio cal BC de Vilches IV (Hellín, Albacete), Lucentum 37, 33-54.

DOI: https://doi.org/10.14198/LVCENTVM2018.37.02

JOVER, F. J.; TORREGROSA, P. (2010): Cocinado, servicio, conservación y almacenamiento: hacia una caracterización del repertorio cerámico, La Torreta-El Monastil (Elda, Alicante): del IV al III milenio AC en la cuenca del río Vinalopó (F. J. Jover, coord.), Alicante, 187-218.

JOVER, F. J.; TORREGROSA, P.; GARCÍA ATIÉNZAR, G. (coords.) (2014): El Neolítico en el Bajo Vinalopó (Alicante, España), B.A.R.-I.S., 2646, Oxford.

JUAN-CABANILLES, J. (1990): Estructuras de habitación en la Ereta del Pedregal (Navarrés, Valencia). Resultados de las campañas de 1980-1982 y 1990, Sagvntvm-PLAV 27, 67-97, < http://ojs.uv.es/index.php/saguntum/article/view/2226>.

JUAN-CABANILLES, J. (2005): Las manifestaciones del Campaniforme en el País Valenciano: una visión sintética, El campaniforme en la Península Ibérica y su contexto europeo (M. A. Rojo, R. Garrido, I. García Martínez de Lagrán, coords.), Valladolid, 389-400.

JUAN-CABANILLES, J.; GARCÍA PUCHOL, O.; FERNÁNDEZ, J. (2006): L'utilisation du silex en plaquettes dans la Préhistoire récente du Pays Valencien (Espagne méditerranéenne), La fin de l'Age de Pierre en Europe du Sud. Matériaux et productions lithiques taillées remarquables dans le Néolithique et le Chalcolithique du sud de l'Europe (J. Vaquer, F. Briois, dirs.), Toulouse, 273-284.

KUNST, M. (2017): Campaniforme em Zambujal (Torres Vedras), Sinos e Taças. Junto ao Oceano e mais longe. Aspectos da presença campaniforme na Península Ibérica (V. S. Gonçalves, ed.), Lisboa, 194-212.

LIESAU, C.; BLASCO, C.; RÍOS, P.; VEGA, J.; MENDUIÑA, R.; BLANCO, J. F.; BAENA, J.; HERRERA, T.; PETRI, A.; GÓMEZ, J. L. (2008): Un espacio compartido por vivos y muertos: El poblado calcolítico de fosos de Camino de las Yeseras (San Fernando de Henares, Madrid), Complutum, 19 (1), 97-120, <https://revistas.ucm.es/index.php/CMPL/ article/view/CMPL0808110097A>.
LÓPEZ PADILLA, J. A. (2006): Consideraciones en torno al "Horizonte Campaniforme de Transición”, APL XXVI, 193244, <http://mupreva.org/pub/774/es>.

LÓPEZ PADILLA, J. A. (2010): L'ocupació prehistòrica del Castellar, El Castellar d'Elx. L'origen de la ciutat medieval (P. Guichard, S. Gutiérrez, J. L. Menéndez, coords.), Elche, 25-29.

LÓPEZ PADILLA, J. A.; DE MIGUEL, M. P.; ARNAY DE LA ROSA, M.; GALINDO, L.; ROLDÁN, C.; MURCIA, S. (2012): Ocre y cinabrio en el registro funerario de El Argar, TP 69 (2), 273-292.

DOI: https://doi.org/10.3989/tp.2012.12092

LÓPEZ SEGUÍ, E. (1995): El alfar ibérico de El Arsenal (Elche, Alicante), Actas del XXII Congreso Nacional de Arqueología: Vigo, 1993, v. II, Vigo, 231-234.

LÓPEZ SEGUÍ, E. (2000): La alfarería ibérica en Alicante. Los alfares de la Illeta dels Banyets, La Alcudia y el Tossal de Manises, Íbers. Agricultors, artesans i ramaders. III Reunió sobre Economia en el mon ibèric (C. Mata, G. Pérez Jordà, eds.), Saguntum Extra-3, València, 245-248, < https:// ojs.uv.es/index.php/saguntumextra/article/view/2868>.

LÓPEZ SEGUÍ, E.; ESPÍ, I. (2010): Memoria excavación arqueológica realizada en el P.P. Sector E-16 Portes Encarnades, Elche (Alicante) (inédita), Alicante.

MOLINA, F.; CÁMARA, J. A. (2005): Guía del yacimiento arqueológico Los Millares, Sevilla.

MOLINA, F.; CÁMARA, J. A.; DELGADO, A.; JIMÉNEZ, S. A.; NÁJERA, T.; RIQUELME, J. A.; SPANEDDA, L. (2016): Problemas cronológicos y análisis de dieta en la Edad del Bronce de los Altiplanos granadinos: el caso del Cerro de la Virgen (Orce, Granada, España), Del neolític a l'edat del bronze en el Mediterrani occidental. Estudis en Homenatge a Bernat Martí Oliver, Trabajos Varios. S.I.P. 119, València, 451-463, <https://mupreva.org/pub/920/es>.

MOLINA, F.; CÁMARA, J. A.; DORADO, A.; VILLARROYA, M. (2017): El fenómeno campaniforme en el Sudeste de la Península Ibérica: el caso del Cerro de la Virgen (Orce, Granada), Sinos e Taças. Junto ao Oceano e mais longe. Aspectos da presença campaniforme na Península Ibérica (V. S. Gonçalves, ed.), Lisboa, 258-274.

MUÑOZ,A. M. (1993): Neolítico final-Calcolítico en el sureste peninsular: El Cabezo del Plomo (Mazarrón, Murcia), Espacio, tiempo y forma. Serie I, Prehistoria y Arqueología 6, 133-180. DOI: https://doi.org/10.5944/etfi.6.1993.4583

ODRIOZOLA, C. P. (2019): La decoración con rellenos de pasta en las cerámicas campaniformes, ;Un brindis por el príncipe! El vaso campaniforme en el interior de la Península Ibérica (2500-2000 A.C.), tomo 2 (G. Delibes, E. Guerra, coords.), Madrid, 11-22.

ODRIOZOLA, C. P.; HURTADO, V.; GUERRA DOCE, E.; CRUZAUÑÓN, R.; DELIBES DE CASTRO, G. (2012): Los rellenos de pasta blanca en cerámicas campaniformes y su utilización en la definición de límites sociales, Estudos Arqueológicos de Oeiras 19, 143-154. 
PASCUAL BENITO, J. LL. (1998): Utillaje óseo, adornos e ídolos neolíticos valencianos, Trabajos Varios. S.I.P. 95, València.

PASTOR, M. (2017): La construcción con tierra en Arqueología: teoría, método, técnicas y aplicación, Alicante.

PAU, C. (2016): Los objetos de adorno en el Mediterráneo occidental en época campaniforme y su trascendencia social, Tesis Doctoral, Universidad de Granada, <http://hdl.handle. net/10481/43488> (Consulta 15-VI-2020).

RAMOS FERNÁNDEZ, R. (1981): El Promontorio de l'Aigua Dolça i Salà de Elche. Avance a su estudio, APL XVI, $197-$ 222, <http://mupreva.org/pub/587/es>.

RAMOS FERNÁNDEZ, R. (1982): Aportaciones estratigráficas para el conocimiento del campaniforme en Elche, Homenaje al Prof. Martín Almagro Basch, tomo II, Madrid, 7-12.

RAMOS FERNÁNDEZ, R. (1983): Precisiones evolutivas sobre cerámicas de tipo campaniforme, Crónica del XVI Congreso Nacional de Arqueología, Zaragoza, 113-120.

RAMOS FERNÁNDEZ, R. (1984a): Formas y motivos decorativos de la cerámica de tipo Campaniforme de Elche, El Eneolítico en el País Valenciano: Actas de coloquio (Alcoy, 1-2 de diciembre de 1984), Alicante, 131-138.

RAMOS FERNÁNDEZ, R. (1984b): Memoria de las excavaciones realizadas en el Promontori de Elche durante las campañas 1980-81, NAH 19, 9-33.

RAMOS FOLQUÉS, A. (1953): Mapa arqueológico del término municipal de Elche (Alicante), AEA 88, 323-354.

RAMOS FOLQUÉS, A. (1954): La Alcudia. Campañas 1940-1948, NAH II (1-3), 107-133.

RAMOS FOLQUÉS, A. (1989): El Eneolítico y la Edad del Bronce en la comarca de Elche, Elche.
RAMOS MOLINA, A. (1989): Presencia neolítica en La Alcudia de Elche, XIX Congreso Nacional de Arqueología (Castellón de la Plana, 1987), v. I, Zaragoza, 161-176.

RUIZ, E. (1990): El fenómeno campaniforme en la provincia de Alicante, Ayudas a la investigación 1986-87, Alicante, 71-80.

SÁEZ, L.; SCHÜLE, W. (1985): Informe preliminar sobre los trabajos y estudio de material del Cerro de la Virgen de Orce (Granada), 1985, Anuario Arqueológico de Andalucía 1985. Actividades sistemáticas, informes y memorias (F. Olmedo coord.), Sevilla, 263-271.

SCHÜLE, W.; PELLICER, M. (1966): El Cerro de la Virgen, Orce (Granada) I, Madrid.

SERNA, I. (2019): El asentamiento de El Arsenal (Elche): espacios domésticos y territorio durante el Campaniforme en el sureste peninsular, DAMA 4, 11-27.

DOI: https://doi.org/10.14198/dama.2019.4.02

SOLER, J. A. (2002): Cuevas de inhumación múltiple en la Comunidad Valenciana. Alicante-Madrid.

SOLER, J. A.; BELMONTE, D. (2006): Vestigios de una ocupación previa a la Edad del Bronce. Sobre las estructuras de habitación prehistórica en la "Illeta dels Banyets", El Campello, Alicante, La ocupación prehistórica de la Illeta dels Banyets (El Campello, Alicante) (J.A. Soler, coord.), Alicante, 27-66.

SOLER, J. A.; LÓPEZ PADILLA, J. A. (2000-2001): Nuevos datos sobre el poblamiento entre el Neolítico y la Edad del Bronce en el sur de Alicante. Lucentum XIX-XX: 7-26. DOI: https://doi.org/10.14198/LVCENTVM2000-2001.19-20.01

SOLER, J. A.; LÓPEZ PADILLA, J. A.; GARCÍA ATIÉNZAR, G.; FERRER GARCÍA, C.; LUJÁN, A. (2014): Excavaciones arqueológicas en la Platja del Carabassí (Elche), El Neolítico en el Bajo Vinalopó (Alicante, España) (F. J. Jover, P. Torregrosa, G. García Atiénzar, coords.), Oxford, 101-121. 